\title{
Pearl Millet: A Climate-Resilient Nutricereal for Mitigating Hidden Hunger and Provide Nutritional Security
}

\author{
C. Tara Satyavathi ${ }^{1 *}$, Supriya Ambawat ${ }^{1}$, Vikas Khandelwal ${ }^{1}$ and Rakesh K. Srivastava ${ }^{2}$ \\ ${ }^{1}$ Indian Council of Agricultural Research - All India Coordinated Research Project on Pearl Millet, Jodhpur, India, \\ ${ }^{2}$ Department of Molecular Breeding (Genomics Trait Discovery), International Crops Research Institute for Semi-arid Tropics, \\ Patancheru, India
}

\section{OPEN ACCESS}

Edited by:

Palak Chaturvedi,

University of Vienna, Austria

Reviewed by:

Mehanathan Muthamilarasan,

University of Hyderabad, India

Arindam Ghatak,

University of Vienna, Austria

Ajit Singh,

University of Nottingham Malaysia Campus, Malaysia

*Correspondence:

C. Tara Satyavathi

csatyavathi@gmail.com

Specialty section: This article was submitted to

Plant Breeding,

a section of the journal

Frontiers in Plant Science

Received: 28 January 2021

Accepted: 03 August 2021

Published: 13 September 2021

Citation:

Satyavathi CT, Ambawat $S$, Khandelwal $V$ and Srivastava RK (2021) Pearl Millet: A Climate-Resilient Nutricereal for Mitigating Hidden Hunger and Provide Nutritional Security. Front. Plant Sci. 12:659938. doi: 10.3389/fpls.2021.659938
Pearl millet [Pennisetum glaucum (L.) R. Br.] is the sixth most important cereal crop after rice, wheat, maize, barley and sorghum. It is widely grown on 30 million ha in the arid and semi-arid tropical regions of Asia and Africa, accounting for almost half of the global millet production. Climate change affects crop production by directly influencing biophysical factors such as plant and animal growth along with the various areas associated with food processing and distribution. Assessment of the effects of global climate changes on agriculture can be helpful to anticipate and adapt farming to maximize the agricultural production more effectively. Pearl millet being a climate-resilient crop is important to minimize the adverse effects of climate change and has the potential to increase income and food security of farming communities in arid regions. Pearl millet has a deep root system and can survive in a wide range of ecological conditions under water scarcity. It has high photosynthetic efficiency with an excellent productivity and growth in low nutrient soil conditions and is less reliant on chemical fertilizers. These attributes have made it a crop of choice for cultivation in arid and semi-arid regions of the world; however, fewer efforts have been made to study the climate-resilient features of pearl millet in comparison to the other major cereals. Several hybrids and varieties of pearl millet were developed during the past 50 years in India by both the public and private sectors. Pearl millet is also nutritionally superior and rich in micronutrients such as iron and zinc and can mitigate malnutrition and hidden hunger. Inclusion of minimum standards for micronutrients-grain iron and zinc content in the cultivar release policy-is the first of its kind step taken in pearl millet anywhere in the world, which can lead toward enhanced food and nutritional security. The availability of high-quality whole-genome sequencing and re-sequencing information of several lines may aid genomic dissection of stress tolerance and provide a good opportunity to further exploit the nutritional and climate-resilient attributes of pearl millet. Hence, more efforts should be put into its genetic enhancement and improvement in inheritance to exploit it in a better way. Thus, pearl millet is the next-generation crop holding the potential of nutritional richness and the climate resilience and efforts must be targeted to develop nutritionally dense hybrids/varieties tolerant to drought using different omics approaches.

Keywords: pearl millet, climate-resilience, drought tolerance, abiotic stress, nutritional security 


\section{INTRODUCTION}

The changing climate is leading to an increase in global average temperature affecting agricultural production worldwide. Further, it directly influences biophysical factors such as plant and animal growth along with the different areas associated with food processing and distribution. Assessment of effects of global climate changes and deployment of new tools and strategies to mitigate their effect is crucial to maximizing agricultural production to meet out food demands of the increasing population. In this context, pearl millet is most useful as it is a nutritious, climate change-ready crop with enormous potential for yielding higher economic returns in marginal conditions in comparison with other cereals even in case of climate change with harsh temperature conditions. Moreover, it has greater ceiling temperatures for grain yield and is an underutilized crop with huge nutritional potential, which needs to be utilized fully (Krishnan and Meera, 2018). It is more resilient to extreme climatic events such as drought and water scarcity and can play a vital role in ensuring food and nutritional security in changing climatic scenarios, which is mounting to frightening proportions. Globally, it is the sixth most significant cereal crop after rice (Oryza sativa), wheat (Triticum aestivum), maize (Zea mays), barley (Hordeum vulgare) and sorghum (Sorghum bicolor). It is a staple food of 90 million poor people and extensively grown on 30-million-ha area in the arid and semi-arid tropical regions of Asia and Africa. It is also used for feed and fodder and accounts for almost half of the global millet production (Srivastava et al., 2020a). It is mainly cultivated on marginal lands under rainfed conditions and can sustain and produce a significant amount of grain even in drought-prone areas that receive an average annual precipitation of $<250 \mathrm{~mm}$ (Nambiar et al., 2011). It surpasses all other cereals such as wheat, maize, rice, sorghum and barley because of its unique attributes like the $\mathrm{C}_{4}$ plant having high photosynthetic efficiency, more dry matter production capability, and survival under adverse agro-climatic conditions with lesser inputs and more economic returns (Nambiar et al., 2011). $\mathrm{C}_{4}$ plants have more ability to fix inorganic $\mathrm{CO}_{2}$ and more efficient in water utilization in comparison with $\mathrm{C}_{3}$ plants due to the presence of "Kranz" anatomy in leaves. Thus, being a $\mathrm{C}_{4}$ plant, pearl millet can account for $30 \%$ of global terrestrial carbon fixation along with other $\mathrm{C}_{4}$ plants such as maize and sorghum (Choudhary et al., 2020). It also possesses several advantages such as early maturity, drought tolerance, the requirement of minimal inputs, and usually free from biotic and abiotic stresses. Its inherent ability to endure high temperatures up to $42^{\circ} \mathrm{C}$ during the reproductive phase makes it suitable for growth in extremely hot summers under irrigations in northern Gujarat and eastern Uttar Pradesh of India, thus making it a climateresilient crop.

It also possesses the huge capability to eliminate micronutrient deficiency among developing countries (Rai et al., 2012; Anuradha et al., 2017; Singhal et al., 2018) as it supplies 30$40 \%$ of inorganic nutrients and bestows affordable staple food along with ample amounts of iron and zinc (Rao et al., 2006). It has very high nutritional values and is a good source of energy, carbohydrates, crude fibers [resistant starch (RS), soluble and insoluble dietary fibers], soluble and insoluble fat, proteins (8$19 \%)$, ash, dietary fibers $(1.2 \mathrm{~g} / 100 \mathrm{~g})$, antioxidants and fat (3-8\%) with better fat digestibility, iron, and zinc in comparison with other major cereals (Uppal et al., 2015). It is also a rich source of vitamins such as riboflavin, niacin, and thiamine and minerals $(2.3 \mathrm{mg} / 100 \mathrm{~g})$ such as potassium, phosphorous, magnesium, iron, zinc, copper, and manganese (Weckwerth et al., 2020). It exhibits a better essential amino acid profile of protein in comparison with other cereals such as maize and rice. It contains lesser cross-linked prolamins leading to higher digestibility of the millet proteins. It has $74 \%$ polyunsaturated fatty acids (PUFAs) and rich in nutritionally sought-after omega-3 fatty acids such as oleic acid (25\%), linoleic acid (45\%), and linolenic acid (4\%), which are considered best for health (Rooney, 1978; Nantanga, 2006; Dyall, 2015; Singh et al., 2018). It is a gluten-free grain that retains alkaline properties even after being cooked and is thus good for people suffering from gluten allergy. It owns a higher quantity of slowly digestible starch (SDS) and RS that account for lower glycemic index (GI) and is much preferred in recent times of transforming diets, food habits and the food industry (Satyavathi et al., 2020). It is a highly nutritious, nonacid-forming, non-glutinous food having several nutraceuticals and health beneficial properties along with high fiber content. It acts as a probiotic food for microflora present in our body and keeps us away from constipation. It is also capable of lowering cholesterol due to the presence of niacin in its grain. It contributes to an antioxidant activity with phytates, polyphenols etc. Consumption of various types of millets is considered to protect against certain types of cancer, cardiovascular diseases and various age-related diseases. Due to these useful properties, pearl millet is gaining a lot of popularity among health-conscious people all over the world. Due to its nutritional properties, pearl millet has been renamed as nutri-cereal (Gazette of India, No. 133 dated 13 April, 2018) and can play a vital role in overcoming malnutrition and ensure food and nutritional security.

In the present-changing climatic scenario, abiotic stresses entail a huge risk for plant growth and development leading to an over $50 \%$ decrease in the yield among the popular cereal crops (Bray et al., 2000). Almost $90 \%$ of the cultivable land is affected by various abiotic stresses globally, while only $10 \%$ of the agricultural land is free from these abiotic stresses (Dita et al., 2006). Drought and heat are the two most significant production constraints existing among the different environmental stresses. In this context, a crop species like pearl millet, which is resilient to higher temperatures and lower rainfall, can play a crucial role in fulfilling the increasing food demands of the growing population of the world. Pearl millet is mainly cultivated on marginal lands facing untimely and irregular rainfall patterns and environmental stresses due to its natural inbuilt capacity to survive in such areas and withstand abiotic stresses such as drought, salinity, heat etc. (Serba and Yadav, 2016). Genetic improvement of pearl millet through increased production was realized using hybrid technology and conventional breeding methods of selection (Yadav and Rai, 2013; Yadav et al., 2021) but later, various biotechnological and genomic approaches were used for further improvement (Varshney et al., 2017; Bollam et al., 2018; Ambawat et al., 2020). Genetic maps, next-generation 
sequencing (NGS), genotyping-by-sequencing (GBS), genomewide association studies (GWAS), synteny studies, expression profiling, fine QTL mapping, candidate gene identification and genetic engineering, gene pyramiding, bioinformatics and systems biology are some of the useful platforms, which are further being used for the genetic improvement of this nutricereal. Recently reported genome sequence information in the year 2017 can speed up gene innovation and trait mapping and can help in the understanding of several complicated gene pathways and their interactions (Varshney et al., 2017). Further, the challenge remains to characterize thousands of genes crucial for abiotic stress response and tolerance. Similarly, there is a high need to identify the lines that can use nitrogen efficiently as most of the agro-ecologies where pearl millet is grown have low $\mathrm{N}$ in the root zone soil strata.

In addition, integrated knowledge on genomics as well as transcriptomics, proteomics and metabolomics is also beneficial for advancements and biofortification of pearl millet (Dita et al., 2006; Lata, 2015; Anuradha et al., 2017; Ambawat et al., 2020). Hence, there is a need to focus on this very important crop and harness its suitability to adverse conditions and utilize its inbuilt capacity to ensure global food and nutritional security. Here, we have reviewed the importance of pearl millet in the presentchanging climatic scenario for food and nutritional security and various advances made in the pearl millet improvement program.

\section{STATUS OF PEARL MILLET PRODUCTION}

Pearl millet is a descendent of the wild West African grass and was domesticated over 4,000 years ago in the West African Sahel, spreading later to East Africa and India (Sharma et al., 2021). Now it is being cultivated over 30 million ha worldwide, with the majority of the crop grown in Africa ( $>18$ million ha) and Asia (>10 million ha) (Raheem et al., 2021). Around 90 million people in the Sahelian region of Africa and northwestern India consume pearl millet grain as a staple food (Srivastava et al., 2020b). Jukanti et al. (2016) have reviewed the origin and evolutionary history of pearl millet. It is the sixth major cereal crop in the world followed by maize, rice, wheat, barley and sorghum and cultivated on 30 million ha in the arid and semi-arid tropical regions of Asia and Africa accounting for around half of the global millet production with $60 \%$ of the cultivation area in Africa, followed by $35 \%$ in Asian countries. In terms of area and production, India is the largest producer of pearl millet. During 2010-2012, the average pearl millet area in India was 8.5 million ha and the average production was 9.4 million tons. It is taken up in an area of 6.93 million ha with an average production of 8.61 million tones and $1,243 \mathrm{~kg} / \mathrm{ha}$ productivity (Directorate of Millets Development, 2020). The trends of area, production, and productivity over the years are shown in Figure 1. In Africa, the west/central Africa (WCA) region (Nigeria, Niger, Chad, Mali, and Senegal), and east/southern Africa (ESA), which includes Sudan, Ethiopia, and Tanzania, are the two main areas of pearl millet cultivation. Pearl millet is the third major crop in sub-Saharan Africa with Nigeria, Senegal, Chad, Mali, Niger and Burkina Faso as the major producing countries and has socio-economic, food/feed, health and environmental impact on the resource-poor people of Africa. WCA is the largest pearl millet-producing region in Africa and the world, accounting for $95 \%$ of the total area in WCA (Jukanti et al., 2016). West Africa is the largest producer led by Nigeria (41\%), Niger (16\%), Burkina Faso (7\%), Mali (6.4\%), and Senegal and Sudan (4.8\%). In Africa, it is produced in 18.50 million ha by 28 countries with a yield of 11.36 million tons covering $30 \%$ different areas of the continent in diverse agroecologies. It is $49 \%$ of the global millet area with great significance (FAO, 2019).

It is extensively cultivated in India and is the fourth most extensively grown cereal crop after rice, wheat and maize. Rajasthan, Maharashtra, Uttar Pradesh, Gujarat, and Haryana are the major pearl millet-growing states, contributing $90 \%$ of the total production in India. Out of this, Rajasthan contributes a maximum of around 4.283 million 5 tonnes, followed by Uttar Pradesh (1.302), Haryana (1.079), Gujarat (0.961), Maharashtra (0.66), and Tamil Nadu (0.084). It is mainly cultivated in the rainy (kharif) season (June/July-September/October) but it is also grown in some parts of Gujarat, Rajasthan, and Uttar Pradesh during the summer season (February-May), while it is also cultivated in states of Maharashtra and Gujarat at a small scale during the post-rainy ( $r a b i$ ) season (November-February). As millets are climate-smart crops with nutritional value, they are rightly termed as nutricereals (Gazette of India, No. 133 dated 13 April, 2018). In addition, to include millets into the mainstream and exploit its nutritionally superior qualities and promote its cultivation, Government of India has declared Year 2018 as the "Year of Millets" and FAO Committee on Agriculture (COAG) forum has declared Year 2023 as "International Year of Millets."

\section{PEARL MILLET IMPROVEMENT}

Indian Council of Agricultural Research started pearl millet breeding in India in the 1940s, and X1 and X2 were the two chance hybrids released in India for commercial utilization in the fifties (Yadav and Rai, 2013). Pearl millet improvement programs were implemented in several phases. During phase I, breeders mainly focused on the flowering habit, mode of pollination, germplasm evaluation and enhancement, genetics and cytogenetics of agronomically important traits, cytoplasmic male sterility (CMS) etc. Thus, initially, efforts were put forward towards the identification and use of dwarfing genes for enhancing the yield using locally adapted materials and various Open Pollinated Varieties (OPVs) were developed. As a result of this, pearl millet hybrid research has gained importance in India and the productivity was $4.5 \mathrm{~kg} / \mathrm{ha} /$ year during this phase (Yadav et al., 2019). By the 1960s, hybrid development became the major objective of breeding for enhancing pearl millet production and productivity. Hybrid "HB-1" (Hybrid Bajra-1) was the first pearl millet hybrid released in 1965 (Athwal, 1965) followed by a series of hybrids between 1965 and 1988 and during phase II, an annual increase of $6.6 \mathrm{~kg} / \mathrm{ha}$ was achieved in productivity.

The genetic improvement program progressed effectively initiating from the selection of local and traditional germplasm to the development of high-yielding hybrids possessing inbuilt 


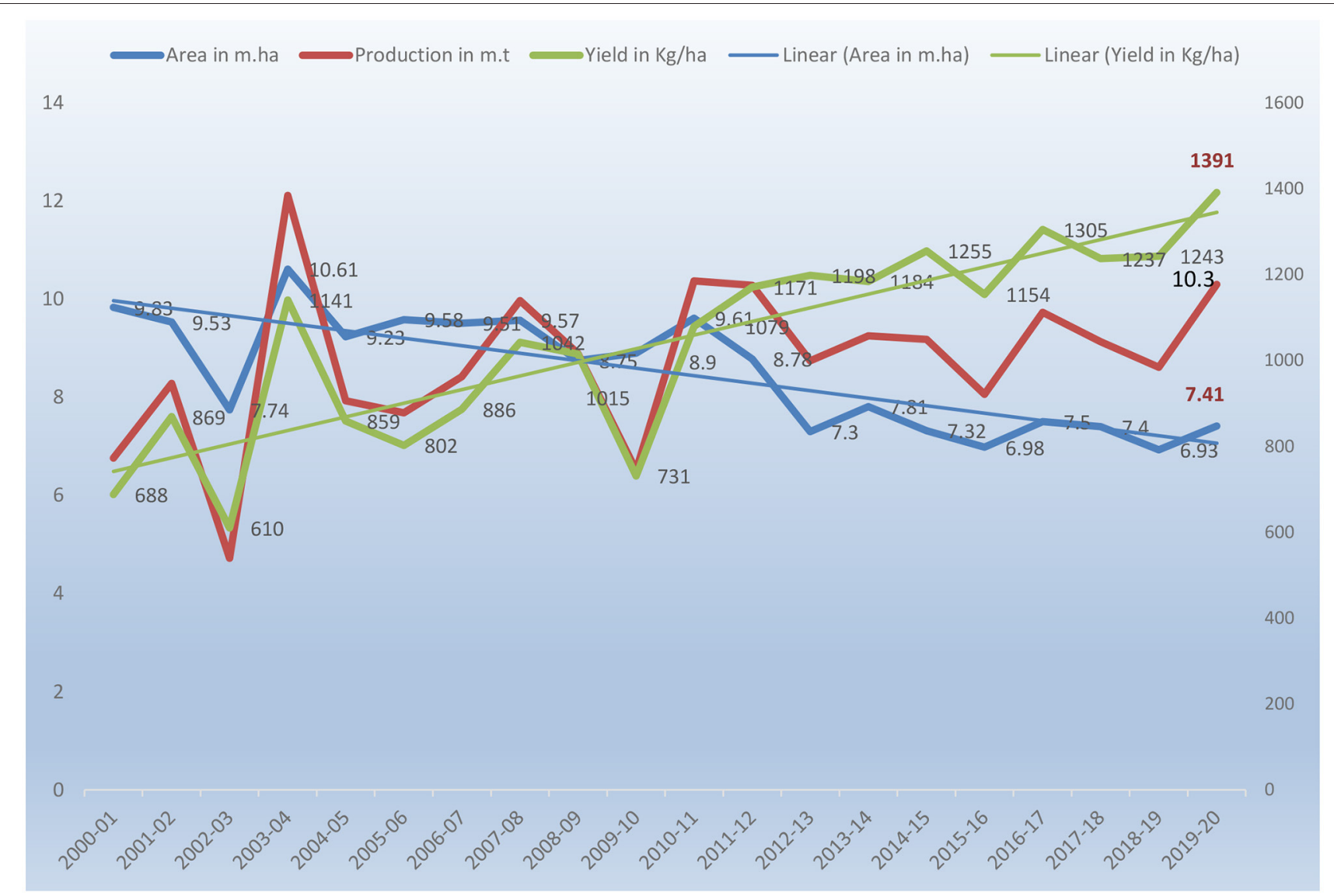

FIGURE 1 | Area, production and productivity of Pearl millet in India since 2000.

tolerance and resistance to climatic stresses such as drought and heat along with different diseases. These hybrids were grown on $70 \%$ of the total pearl millet area, resulting in a $124 \%$ enhancement in productivity since 1986-1990. ICAR-All India Coordinated Research Project on Pearl Millet has developed several precise production and protection technologies for different agro-ecological regions of different states since its beginning in 1965. Till now, a total of 180 hybrids and 62 varieties have been identified and released for growing in different agroecological regions of India through ICAR-All India Coordinated Research Project on Pearl millet (Satyavathi et al., 2020). Several genetically diverse CMS lines have been developed and used along with marker-assisted breeding (MAB) and marker-assisted backcrossing, resulting in an increased productivity to 19.0 $\mathrm{kg} / \mathrm{ha} /$ year during phase III (Yadav et al., 2019).

During the fourth phase, great emphasis was laid on the genetic diversity of seed and pollinator parents and adaptation to niche areas, resulting in the release of a large number of cultivars and a significant increase in productivity $31.1 \mathrm{~kg} / \mathrm{ha} /$ year, which was almost five times in comparison with Green Revolution Era (Govindaraj et al., 2010; Kumara et al., 2014; Yadav et al., 2019). In the next phase, biofortification of the grain for micronutrients, largely for zinc and iron and application of molecular techniques were focused to speed up the cultivar development program (Rai et al., 2013; Kanatti et al., 2016, Kumar et al., 2016, 2018; Anuradha et al., 2017; Singhal et al., 2018; Govindaraj et al., 2019). These cultivars were widely adopted by Indian farmers resulting in enhanced crop productivity from $305 \mathrm{~kg} / \mathrm{ha}$ during 1951-1955 to $998 \mathrm{~kg} / \mathrm{ha}$ during 2008-2012 and 1,243 kg/ha during 201819 (Yadav and Rai, 2013; Satyavathi et al., 2020) (Figure 2). The productivity during the 5 years starting from 1951 to 1955 (305 $\mathrm{kg} / \mathrm{ha}$ ) has increased to $1,290 \mathrm{~kg} / \mathrm{ha}$ for the 5 years $2016-2020$. The productivity improvement is four-fold, or 400\%. Compared to the previous 5 years term of 2011-2015, the productivity was $1,192 \mathrm{~kg} / \mathrm{ha}$, while it is $1,290 \mathrm{~kg} / \mathrm{ha}$ for the 5 years $2016-2020$. The improvement is $7.6 \%$ compared to the period of $2011-$ 2015. This improvement is due to the combined contribution of the development of high-yielding hybrids, varieties, biofortified genotypes, improved production practices, technologies, and recommendations coupled with adoption by farmers.

Several efforts were taken for crop improvement in pearl millet using conventional as well as advanced molecular and genomic tools as listed in Tables 1, 2. Pearl millet is the first crop in which marker-assisted-selection (MAS) strategies and tools were applied to get improved varieties. Yadav et al. (2021) discussed various past strategies and future approaches 


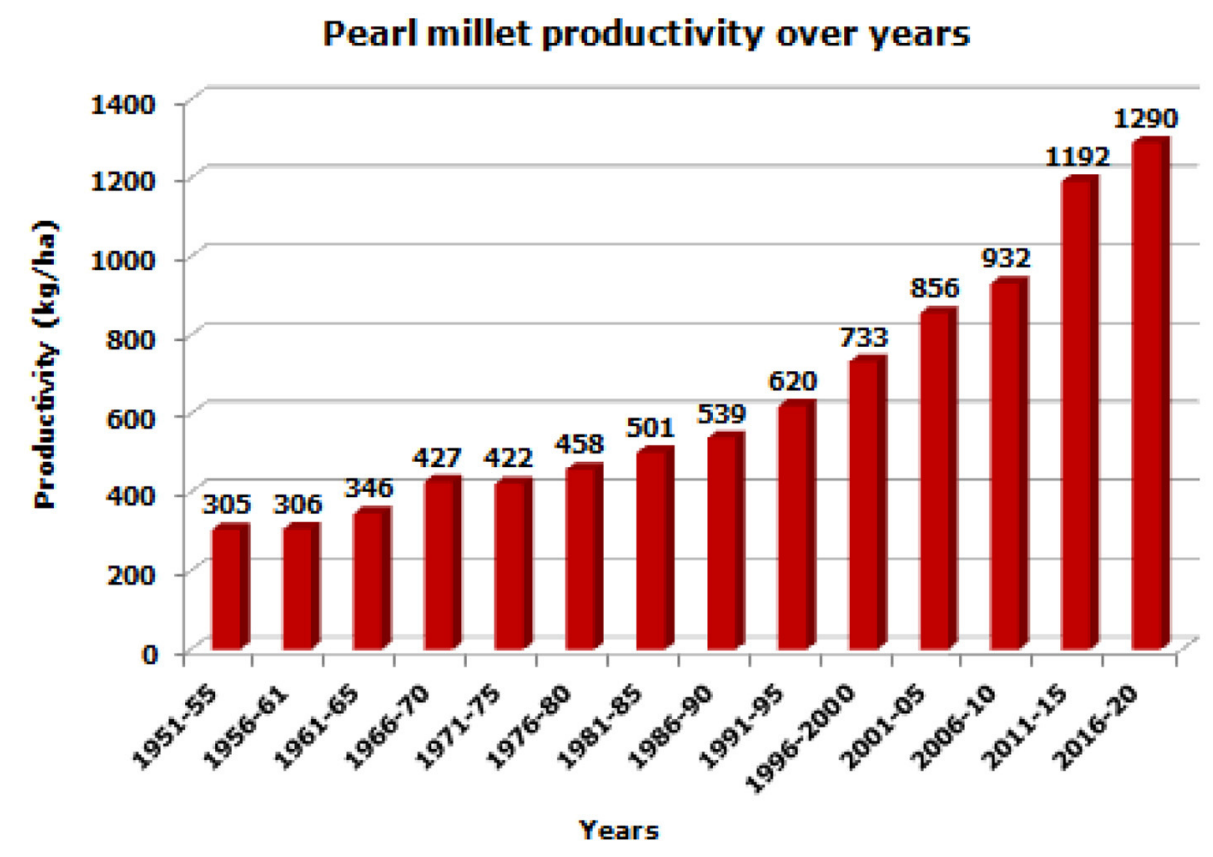

FIGURE 2 | Trends in pearl millet productivity over years (based on 5-year average).

to accelerate genetic gains to meet future demand. Further, they also emphasized the importance of genome editing, prebreeding, precision phenotyping protocols and speed breeding approaches for pearl millet improvement and enhanced genetic gains. On the other hand, due to a lack of knowledge and nonavailability of ideal dose of fertilizer among poor farmers, it becomes difficult to harvest the real yield potential. Hence, the yield improvement of pearl millet under low nitrogen input is indeed beneficial for economic and environmentally sustainable cultivation. Pujarula et al. (2021) studied the genetic variation for nitrogen-use efficiency (NUE) among a set of 380 diverse pearl millet lines. Thus, such studies of different physiological traits and their relationship with grain yield are very important for understanding the complex nature of NUE.

\section{CLIMATE RESILIENCE IN PEARL MILLET AND GENOMIC RESOURCES}

Pearl millet can survive and produce a large quantity of grain, whereas other cereals such as rice, wheat, maize, sorghum and barley may fail to provide economic benefits under adverse conditions and poor soil. It can provide multiple securities in form of food, fodder, livelihood, nutrition health and ecological benefits, whereas wheat and rice provide only food security, thus making it a crop of agricultural security. Its ability to withstand higher temperature and survival in drought-prone areas and cultivation in parts of Gujarat and eastern Uttar Pradesh of India during hot summers makes it a climateresilient crop for overcoming the adverse effects of the changing climate (Gupta et al., 2015). National Agricultural Research
System (NARS) in India and International Crops Research Institute for the Semi-Arid Tropics (ICRISAT) have played a significant role in developing various improved breeding and parental lines of prospective hybrids. A total of 21,392 germplasm accessions, including 750 accessions of wild species of genera Pennisetum and Cenchrus, collected from 50 countries are conserved at the ICRISAT Genbank, while 8,284 accessions are conserved at the National Bureau of Plant Genetic Resources (NBPGR), New Delhi, India. These lines have been widely used in breeding programs in both the public and private sectors for the development and commercialization of a large number of hybrids (public 70 and private sectors 105 were under cultivation in 2019).

Various molecular markers and genomic tools have been developed and applied for QTLs/genes identification, genetic diversity, and MAB to enhance pearl millet breeding by exploring its genetic potential at the molecular level (Serba and Yadav, 2016; Anuradha et al., 2017; Bollam et al., 2018; Kumar et al., 2018; Singhal et al., 2018; Ambawat et al., 2020; Srivastava et al., 2020a,b). Various molecular markers developed for pearl millet include restriction fragment length polymorphism [RFLP (Liu et al., 1994)], random amplified polymorphic DNA (RAPD), amplified fragment length polymorphism [AFLP (Devos et al., 1995)], sequence-tagged sites [STSs (Allouis et al., 2001)], simple sequence repeat [SSRs (Qi et al., 2004; Meena et al., 2020; Srivastava et al., 2020a)], single-stranded conformation polymorphism-SNP [SSCP-SNP (Bertin et al., 2005)], expressed sequence tag-derived simple sequence repeats [EST-SSRs (Senthilvel et al., 2008; Rajaram et al., 2013)], DArT array technology [DArTs (Senthilvel et al., 2010; Supriya et al., 2011)], conserved intron-specific primers [CISP (Sehgal et al., 
TABLE 1 | Achievements and milestones in pearl millet improvement through conventional/heterosis breeding.

\begin{tabular}{|c|c|c|}
\hline Year & Achievements & References \\
\hline 1940 & $\begin{array}{l}\text { Indian Council of Agricultural } \\
\text { Research started Pearl millet breeding } \\
\text { in India. }\end{array}$ & $\begin{array}{l}\text { Yadav and Rai, } \\
\text { 2013; Singh et al., } \\
2014\end{array}$ \\
\hline 1950 & $\begin{array}{l}\text { X1 and X2 were the two chance } \\
\text { hybrids released in India for } \\
\text { commercial utilization. }\end{array}$ & $\begin{array}{l}\text { Yadav and Rai, } \\
\text { 2013; Singh et al., } \\
2014\end{array}$ \\
\hline 1965 & $\begin{array}{l}\text { First pearl millet hybrid, Hybrid "HB-1" } \\
\text { (Hybrid Bajra-1) was released. }\end{array}$ & Athwal, 1965 \\
\hline 1965 & $\begin{array}{l}\text { Establishment of the ICAR-All India } \\
\text { Coordinated Research Project on } \\
\text { Pearl Millet }\end{array}$ & $\begin{array}{l}\text { Yadav and Rai, } \\
2013\end{array}$ \\
\hline 1997-2008 & $\begin{array}{l}\text { Effective phenotypic screening } \\
\text { techniques and resources were } \\
\text { developed, and resistance breeding } \\
\text { programs were developed. }\end{array}$ & $\begin{array}{l}\text { Thakur and King, } \\
\text { 1988; Singh et al., } \\
\text { 1997; Hash et al., } \\
\text { 1999; Hash and } \\
\text { Witcombe, 2002; } \\
\text { Jones et al., 2002; } \\
\text { Thakur et al., } 2008\end{array}$ \\
\hline 1974-2020 & $\begin{array}{l}\text { Identification and release of } 175 \\
\text { hybrids and } 62 \text { varieties for cultivation } \\
\text { in different agro-ecological zones of } \\
\text { India }\end{array}$ & $\begin{array}{l}\text { Satyavathi et al., } \\
2020\end{array}$ \\
\hline 2018 & $\begin{array}{l}\text { Identified heterotic groups for grain } \\
\text { yield and a total of } 343 \text { hybrid } \\
\text { parental [maintainer (B-) and restorer } \\
\text { (R-)] lines were genotyped with } 88 \\
\text { polymorphic SSR markers. }\end{array}$ & Ramya et al., 2018 \\
\hline 2021 & $\begin{array}{l}\text { Genetic variation studies for NUE } \\
\text { among a set of } 380 \text { diverse pearl } \\
\text { millet lines }\end{array}$ & $\begin{array}{l}\text { Pujarula et al., } \\
2021\end{array}$ \\
\hline 2021 & $\begin{array}{l}\text { Studied expression of heat } \\
\text { stress-responsive gene Pghsp }\end{array}$ & Sankar et al., 2021 \\
\hline
\end{tabular}

TABLE 2 | Achievements and milestones in pearl millet improvement through molecular and advanced genomic tools.

\begin{tabular}{|c|c|c|}
\hline Year & Achievements & References \\
\hline \multicolumn{3}{|c|}{ Molecular markers } \\
\hline 1994 & $\begin{array}{l}\text { Study of } 200 \text { samples of varied pearl } \\
\text { millet lines using RFLP markers to } \\
\text { reveal polymorphism }\end{array}$ & Liu et al., 1994 \\
\hline
\end{tabular}

1995

Development of amplified fragment length polymorphism (AFLP) markers for pearl millet using nuclear genomic sequences

163 AFLP markers were used to study genetic variability within and between pearl millet landraces

Development of STSs markers from BAC clones

Genetic diversity was studied within and between 504 landraces of core collection using RFLP probes

18 SSR markers were developed from genomic sequences in pearl millet

A consensus map of 353 RFLP and 65 SSR markers was developed for the first time.

SSCP-SNP primes were developed from pearl millet EST collections

EST-based SSRs were developed in pearl millet

2011

DArT platform was established for pearl millet, and 574 polymorphic DArT markers were mapped and used to genotype a set of 24 diverse pearl millet inbred lines

2012

Conserved intron-specific primers (CISP) were developed from EST sequences using parents of two mapping populations for 18 genes

Consensus linkage maps based on SSRs were constructed using four RIL populations

2012)], and single nucleotide polymorphisms [SNPs (Sehgal et al., 2012)]. High allelic variation and polymorphism were recorded between pairs of parental lines of pearl millet after screening with SNP markers, and they were also mapped on all the seven linkage groups reflecting the distribution of the markers in the genome (Sehgal et al., 2012). Similarly, a panel 21,663 SNP markers were also discovered, depicting $>5 \%$ of minor allele frequencies by Diack et al. (2020). Different types of molecular markers and genomic approaches ultimately provide a systematic knowledge on plant biology enabling $\mathrm{MAB}$, which can accelerate the process of the development of new and resistant hybrids/varieties.

MAS and gene introgression into desirable genetic background have been proved to be very efficient for crops improvement as it reduces the cumbersome procedure of phenotypic evaluation and selection. Pearl millet is one of the crops where MAB approach has been applied to develop downy mildew-resistant variety "Improved HHB 67" (Hash et al., 2006). Later, studies were also conducted to identify and map major QTLs affecting abiotic stress tolerance in pearl millet (Yadav et al., 1999, 2002, 2004, 2011; Serraj et al., 2005; Bidinger et al., 2007; Kholová et al., 2012, 2013; Tharanya et al., 2018). The first
2013 Genetic diversity was analyzed in a novel set of restorer lines using SSR markers in pearl millet

2014 Development of ISSR-based SCAR markers in pearl millet

2015 Identification of single nucleotide polymorphisms (SNPs) using GBS platform

2020 A panel of 21,663 SNP markers was developed

2020

Morphological and molecular genetic diversity analysis of pearl millet (Pennisetum glaucum) maintainers and restorers.

QTL mapping 1995-2007

DNA markers have been established for around 60 different putative DM resistance QTLs in pearl millet
Devos et al., 1995

Busso et al., 2000

Allouis et al., 2001; Qi et al., 2001

Bhattacharjee

et al., 2002

Budak et al., 2003

Qi et al., 2004

Bertin et al., 2005

Senthilvel et al., 2008

Supriya et al., 2011

Sehgal et al., 2012

Rajaram et al., 2013

Satyavathi et al., 2013

Jogaiah et al., 2014

Hu et al., 2015; Sehgal et al., 2015

Diack et al., 2020

Chandra et al. 2020

Jones et al., 1995 2002; Hash et al., 1999; Breese et al., 2002; Hash and Witcombe, 2002; Gulia et al., 2007 
TABLE 2 | Continued

\begin{tabular}{|c|c|c|}
\hline Year & Achievements & References \\
\hline 1998 & $\begin{array}{l}\text { Identified molecular markers for three } \\
\text { rust loci and one Magnaporthe } \\
\text { resistance locus in pearl } \\
\text { millet. }\end{array}$ & $\begin{array}{l}\text { Morgan et al., } \\
1998\end{array}$ \\
\hline 1999, 2002 & $\begin{array}{l}\text { QTL was identified for grain and } \\
\text { stover yield in pearl millet under } \\
\text { terminal drought stress } \\
\text { conditions }\end{array}$ & $\begin{array}{l}\text { Yadav et al., 1999, } \\
2002\end{array}$ \\
\hline 2005 & Evaluated putative DT-QTL on LG2 & $\begin{array}{l}\text { Bidinger et al., } \\
\text { 2005; Serraj et al., } \\
2005\end{array}$ \\
\hline 2007 & $\begin{array}{l}\text { Three major QTLs were identified on } \\
\text { LG 2, LG 3, and LG } 4 \text { for grain yield } \\
\text { under variable post-flowering water } \\
\text { conditions }\end{array}$ & $\begin{array}{l}\text { Bidinger et al., } \\
2007\end{array}$ \\
\hline 2010 & $\begin{array}{l}\text { Identified QTL responsible for terminal } \\
\text { drought tolerance }\end{array}$ & $\begin{array}{l}\text { Kholová et al., } \\
2010\end{array}$ \\
\hline 2011 & $\begin{array}{l}\text { Identified one major QTL on LG2 for } \\
\text { grain yield and drought tolerance }\end{array}$ & Yadav et al., 2011 \\
\hline \multirow[t]{2}{*}{2012} & $\begin{array}{l}\text { Co-mapped alleles to terminal } \\
\text { drought tolerance QTL }\end{array}$ & $\begin{array}{l}\text { Kholová et al., } \\
2012\end{array}$ \\
\hline & $\begin{array}{l}\text { Investigated the effects of DT-QTL on } \\
\text { LG } 2 \text { under salinity stress }\end{array}$ & $\begin{array}{l}\text { Sharma et al., } \\
2014\end{array}$ \\
\hline 2015 & $\begin{array}{l}\text { Detected four QTLs linked to high } \\
\text { transpiration rate }\end{array}$ & $\begin{array}{l}\text { Aparna et al., } \\
2015\end{array}$ \\
\hline 2016 & $\begin{array}{l}\text { A major QTL for rust resistance was } \\
\text { identified on LG } 1 \text { using the cross } \\
\text { 81B-P6 } \times \text { ICMP 451-P8 }\end{array}$ & $\begin{array}{l}\text { Ambawat et al., } \\
2016\end{array}$ \\
\hline 2018 & $\begin{array}{l}\text { QTLs were identified on LG } 1 \text { and LG } \\
4 \text { for downy mildew (DM) resistance in } \\
\text { pearl millet }\end{array}$ & Taunk et al., 2018 \\
\hline 2018 & $\begin{array}{l}\text { Identified five QTLs for early drought } \\
\text { stress conditions and stay-green } \\
\text { trait }\end{array}$ & Debieu et al., 2018 \\
\hline 2018 & $\begin{array}{l}\text { Role of chitosan nanoparticles was } \\
\text { explored for resistance against pearl } \\
\text { millet downy mildew }\end{array}$ & $\begin{array}{l}\text { Siddaiah et al., } \\
2018\end{array}$ \\
\hline 2019 & $\begin{array}{l}\text { Introgressed DT-QTLs into hybrid } \\
\text { HHB } 226 \text { from } 863 \mathrm{~B} \text {, the male } \\
\text { parent HBL } 11\end{array}$ & Jangra et al., 2019 \\
\hline 2019 & $\begin{array}{l}\text { Five QTLs were identified for } \\
\text { resistance to three different pathotype } \\
\text { isolates of } S \text {. graminicola }\end{array}$ & $\begin{array}{l}\text { Chelpuri et al., } \\
2019\end{array}$ \\
\hline \multicolumn{3}{|c|}{ Advanced genomic tools } \\
\hline 2006 & $\begin{array}{l}\text { Improved HHB67 was developed } \\
\text { using the marker-assisted selection }\end{array}$ & Hash et al., 2006 \\
\hline 2009 & $\begin{array}{l}\text { GWAS approach was used to dissect } \\
\text { complex traits in pearl millet }\end{array}$ & Saïdou et al., 2009 \\
\hline 2015 & $\begin{array}{l}\text { SNP markers were identified using } \\
\text { genotyping-by-sequencing (GBS) } \\
\text { pearl millet and high-density maps } \\
\text { were constructed. }\end{array}$ & $\begin{array}{l}\text { Hu et al., 2015; } \\
\text { Moumouni et al., } \\
2015\end{array}$ \\
\hline 2015 & $\begin{array}{l}\text { PMiGAP was established and used } \\
\text { for fine mapping of a drought } \\
\text { tolerance DT-QTL on LG2 using } \\
\text { candidate gene-based association } \\
\text { mapping (AM) approach. }\end{array}$ & Sehgal et al., 2015 \\
\hline
\end{tabular}

TABLE 2 | Continued

\begin{tabular}{lll}
\hline Year & Achievements & References \\
\hline 2016 & Transcriptomic analysis was done & Kulkarni et al., \\
& &
\end{tabular}

using NGS tool to understand the 2016

mechanisms underneath resistance

to downy mildew in pearl millet

2016

16,650 SNPs and 333,567 sequence

tags across all seven chromosomes

have been identified for leaf spot

resistance using GBS platform.

2017

A draft genome sequence of $S$.

graminicola pathotype 1 of 299,901,

$251 \mathrm{bp}$ in length, $\mathrm{N}_{50}$ of $17,909 \mathrm{bp}$

with a minimum of $1 \mathrm{~Kb}$ scaffold size

was assembled

Whole-genome sequence of pearl millet was deciphered

A total of 392,493 SNPs identified using GWAS on a panel of 188 inbred lines

Sequencing data were generated for RAD-seq and tGBS using genomic selection (GS) schemes in pearl millet.

Transcriptome analysis for drought stress response using RNA-Seq approach in pearl millet

Genome of Magnaporthe grisea strain PMg_DI and was sequenced, and 13.1-Gb PE reads were generated

Studied the genetic diversity, population structure, and linkage disequilibrium in 398 accessions using GBS

2019 Genetic diversity of 130 forage-type hybrid parents of pearl millet was investigated using GBS-derived 7870 SNPs

Characterized 309 inbred lines by 54,770 GBS-SNPs and reported higher nucleotide diversity in the panel derived from landraces and improved varieties from Africa and India.

Comparative transcriptomics at vegetative and flowering stage was done using RNAseq analysis in a drought-tolerant (PRLT2/89-33) genotype to discover underlying genes to drought tolerance

6920 genes and 6484 genes differentially expressed under heat stress and drought stress were identified using RAD-GBS Heterotic groups were defined and 0.9 million SNPs clustered into $12 \mathrm{R}$ and 7 B-line groups Importance of wild relatives of pearl millet germplasm was harnessed for germplasm enhancement and improving biotic stress tolerance in pearl millet
Punnauri et al., 2016

Nayaka et al., 2017

Varshney et al., 2017

Debieu et al., 2018

Liang et al., 2018

Dudhate et al., 2018; Jaiswal et al., 2018

Prakash et al., 2019

Serba et al., 2019

Ponnaiah et al., 2019

Kanfany et al., 2020

Shivhare et al., 2020

Sun et al., 2020

Gupta et al., 2020

Sharma et al., 2021 
TABLE 2 | Continued

\begin{tabular}{|c|c|c|}
\hline Year & Achievements & References \\
\hline \multicolumn{3}{|c|}{ Quality improvement } \\
\hline 2009-2020 & $\begin{array}{l}\text { Implementation of biofortification } \\
\text { approaches in pearl millet for high Fe } \\
\text { and } \mathrm{Zn}\end{array}$ & $\begin{array}{l}\text { Govindaraj et al., } \\
\text { 2009, 2019, } 2020 \\
\text { Kanatti et al., } \\
\text { 2014; Rai et al., } \\
\text { 2016; Anuradha } \\
\text { et al., } 2017\end{array}$ \\
\hline 2016, 2017 & $\begin{array}{l}\text { Reported diversity in the rancidity } \\
\text { profile of pearl millet genotypes }\end{array}$ & $\begin{array}{l}\text { Datta Mazumdar } \\
\text { et al., 2016; Goyal } \\
\text { and Chugh, } 2017\end{array}$ \\
\hline 2016 & $\begin{array}{l}\text { Identified two QTLs for grain Fe } \\
\text { content on LG3 and LG5, and two } \\
\text { QTLs for grain Zn content on LG3 } \\
\text { and LG7 using replicated samples of } \\
106 \text { pearl millet RILs }\left(F_{6}\right) \text { derived from } \\
\text { ICMB 841-P3 } \times 863 B-P 2 \text { cross. }\end{array}$ & Kumar et al., 2016 \\
\hline 2017 & $\begin{array}{l}\text { Identified favorable alleles for grain } \\
\text { iron and zinc content through AM in } \\
\text { pearl millet. }\end{array}$ & $\begin{array}{l}\text { Anuradha et al., } \\
2017\end{array}$ \\
\hline 2018 & $\begin{array}{l}\text { Reported large effect of Fe and Zn } \\
\text { content QTLs using DArT and SSR } \\
\text { markers in ICMS } \\
\text { 8511-S1-17-2-1-1-B-P03 × AIMP } \\
\text { 92901-S1-183-2-2-B-08 cross. }\end{array}$ & Kumar et al., 2018 \\
\hline 2019 & $\begin{array}{l}\text { RAD-GBS was used and three GS } \\
\text { models were implemented and } \\
\text { compared using grain yield and } \\
\text { dense molecular marker information } \\
\text { of pearl millet }\end{array}$ & $\begin{array}{l}\text { Jarquin et al., } \\
2019\end{array}$ \\
\hline 2020 & $\begin{array}{l}\text { Developed a rancidity matrix (RM) and } \\
\text { classified pearl millet genotypes into } \\
\text { low, medium, and high rancid groups }\end{array}$ & $\begin{array}{l}\text { Goswami et al., } \\
\text { 2020; Kumar } \\
\text { et al., } 2020\end{array}$ \\
\hline 2020 & $\begin{array}{l}\text { Identified candidate genes for grain } \\
\text { Fe and Zn contents in pearl millet }\end{array}$ & $\begin{array}{l}\text { Mahendrakar } \\
\text { et al., } 2020\end{array}$ \\
\hline 2021 & $\begin{array}{l}\text { Mapped multienvironment QTLs for } \\
\text { grain iron and zinc contents in pearl } \\
\text { millet. }\end{array}$ & $\begin{array}{l}\text { Singhal et al., } \\
2021\end{array}$ \\
\hline
\end{tabular}

QTL mapping study was conducted on drought tolerance using recombinant inbred line (RIL) mapping population from the cross H 77/833-2 × PRLT 2/89-33, and a major QTL for drought tolerance (DT-QTL) was mapped on LG 2 explaining 32\% variation for grain yield (Yadav et al., 1999, 2002). Subsequently, fine mapping of the DT-QTL was done and several markers mapped on this region of LG2 were identified, which were found to be linked with traits of drought tolerance, including delayed leaf senescence and leaf rolling under drought stress (Sehgal et al., 2012). Subsequently, Sharma et al. (2014) investigated the effects of DT-QTL under salt stress conditions. Later, Sehgal et al. (2015) utilized PMiGAP for the first time for fine mapping of a drought tolerance (DT) QTL (localized on linkage group 2) using candidate gene-based AM approach. This PMiGAP can be used as a genetic resource for GWAS studies in pearl millet.

Recently, NGS and other advanced high-throughput assays were used to sequence the pearl millet genome, which will prove useful for its improvement and enhancing different yield and yield-related traits along with major biotic and abiotic stress tolerance and nutritionally significant traits worldwide (Varshney et al., 2017). Consequently, GBS, which allows simultaneous SNP discovery and genotyping, has been also used extensively in pearl millet to characterize germplasm (Poland and Rife, 2012; Ramu et al., 2013; Sehgal et al., 2015; Ponnaiah et al., 2019). GBS was used to construct a high-density genetic map with a more uniform distribution of markers in pearl millet from a biparental population in comparison with maps constructed earlier (Moumouni et al., 2015). Similarly, 83,875 SNP markers were identified from PstI-MspI reduced representative libraries of pearl millet by GBS, revealing a wide genetic variation in germplasm collection (Hu et al., 2015). A total of 398 accessions were used to study the genetic diversity, population structure, and linkage disequilibrium using GBS (Serba et al., 2019). Recently, Kanfany et al. (2020) characterized 309 inbred lines derived from landraces and improved varieties of India and Africa by 54,770 GBS-SNPs and reported higher nucleotide diversity in the panel.

Various genetic and genomic resources like GWAS and genomic selection (GS) have been also established in pearl millet, which is useful in trait discovery and whole-genome scan studies. Phenotypic data are combined with GBS data, and different genomic regions governing traits of interest are identified using GWAS. It can be used to exploit the natural diversity available in population or germplasm panels and can be used to increase mapping resolution in comparison with linkage mapping populations (Srivastava et al., 2020a). GS is eventually the extension of marker-assisted selection, and using it, genomewide molecular markers are targeted and promising individuals are selected. It calculates the breeding values by combining marker genotypic data with phenotypic data collected from several environments and pedigree or kinship for improvement in quantitative traits and can ultimately speed up the genetic gain (Meuwissen et al., 2001; Goddard and Hayes, 2007; Heffner et al., 2009). Srivastava et al. (2020a) reviewed various case studies and the development of various whole-genome prediction/GS models based on GWAS which will be highly useful to explore the underlying genetics associated with pearl millet. The use of GWAS approach to dissect complex traits was initially reported in pearl millet by Saïdou et al. (2009). In this study, they revealed the genetic factors controlling the variations in flowering time at the phytochrome C (PHYC) (866 bp) locus, which plays a major role in crop adaptation mechanism. Later, Saidou et al. (2014) investigated an extra region of $100 \mathrm{~Kb}$ around the PHYC gene using the same panel of 90 inbred lines to identify tightly linked best candidate markers. Debieu et al. (2018) also performed GWAS on a panel of 188 inbred lines of West Africa to identify QTLs associated with stay-green trait and biomass production in early drought stress conditions. In addition, different "omics" technologies such as transcriptomics, proteomics, and metabolomics can be also useful for quantitative and qualitative analyses of gene expression allowing more precise use of MAS and transgenic technologies. RNA sequencing (RNASeq) is widely used among the different transcriptome analysis methods as it can efficiently detect unknown genes and novel transcripts and has much potential to study gene expression 


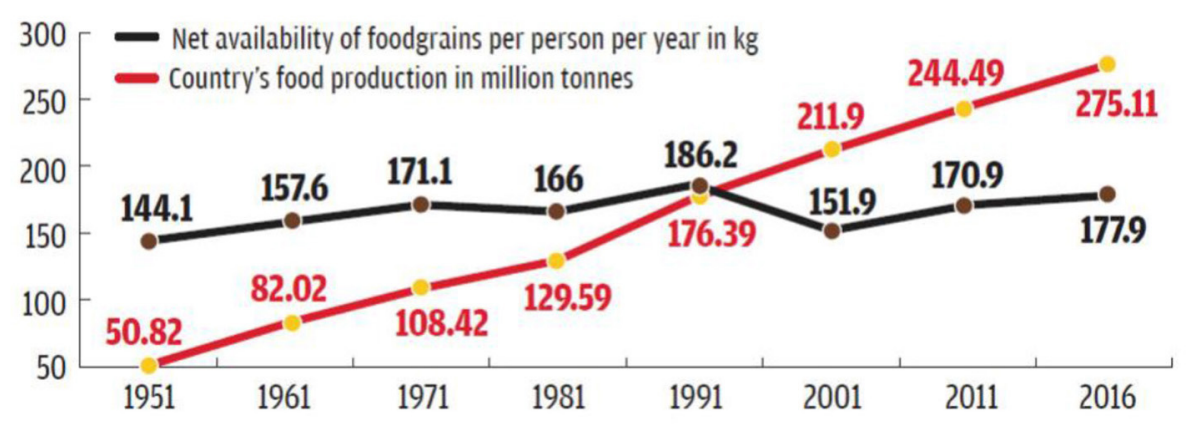

FIGURE 3 | Trends in food grain production and per capita availability in India. Adapted from: Agriculture Statistic, Ministry of Agriculture and Family Welfare.

and their regulating pathways (Hrdlickova et al., 2017). The transcriptome analysis of pearl millet can reflect new prospects into gene regulatory networks existing in this crop under abiotic stress conditions. Stress-regulated pathways in pearl millet can be studied by the detection and characterization of stress-responsive genes via transcriptomics and then different approaches can be followed for improving stress tolerance/resistance in millet (Mishra et al., 2007). Several transcriptomic studies in pearl millet have been used to reveal the functions of some salinity stress-responsive genes such as PgDHN, PgDREB2A, PgVDAC, PgNHX1 (Desai et al., 2006; Mishra et al., 2007; Verma et al., 2007; Agarwal et al., 2010; Reddy et al., 2012; Singh et al., 2015). Recently, complete transcriptome analysis has been done in pearl millet for drought stress response (Dudhate et al., 2018; Jaiswal et al., 2018; Shivhare et al., 2020). Dudhate et al. (2018) unraveled the molecular mechanism governing drought tolerance in two pearl millet inbred lines, ICMB 843 and ICMB 863, using RNA-Seq approach, and it is the first report of the study of drought tolerance by RNA sequencing in pearl millet. More recently, an important study on RNAseq analysis was performed to assess the comparative transcriptomics at the vegetative and flowering stage in a drought-tolerant (PRLT2/8933) genotype to discover underlying genes to drought tolerance (Shivhare et al., 2020).

Proteomics is another important technology to get information on protein concentrations, post-translational modifications (PTMs), protein-protein interaction, structures linked with stress tolerance, regulatory functions of proteins encoded by genes (Ghatak et al., 2017). Identification and characterization of stress-responsive genes and their proteins from pearl millet can help in defining stress-regulated pathways. Further, it can help design strategies to improve stress tolerance/resistance of pearl millet as well as other related crop plants. Several proteomic studies have been also carried out in pearl millet, which can provide a framework to investigate $\mathrm{C}_{4}$ photosynthesis in pearl millet in more depth (Ghatak et al., 2016, 2021; Weckwerth et al., 2020). A shotgun proteomics approach (GEL-LC-Orbitrap-MS) was used by Ghatak et al. (2016) to identify 2,281 proteins from different tissues of pearl millet (root, seed, and leaf) showing significant changes under drought stress condition. Thus, a lot of information has been generated for the improvement of this crop but still, there is a big challenge to identify various crucial genes responsible for its adaption to survival under different abiotic stresses conditions. In addition, the identification of genomic regions governing NUE and its use in pearl millet breeding programs via MAS can be also exploited for survival under adverse conditions. Moreover, exploring several new and advanced genomic tools will be also beneficial for the advancement of this crop to harness its suitability to adverse conditions and utilize its inbuilt capacity to ensure global food and nutritional security.

\section{NUTRITIONAL SECURITY}

Food grain production has increased but still, to feed the growing population and meeting out good health of the people in the present situation, nutritional security is very important (Figure 3).

Intake of all essential macronutrients and micronutrients (vitamins and minerals) through a balanced and diversified diet in sufficient quantities is very vital for an active and healthy life. Nutritional insecurity is a major challenge for the world's growing population, which mainly depends on a micronutrientdeficient cereal-based diet. Pearl millet is the primary source of energy for the semi-arid tropics and drought-prone regions of Asia and Africa after the major cereals such as wheat, rice, maize and sorghum due to its nutritionally superior grain enriched with high amounts of essential amino acids, proteins, better fat digestibility, vitamins and minerals (Table 3). It is a good source of carbohydrate, energy, RS, $92.5 \%$ dry matter, fat (5-7\%), ash (2.1\%), dietary fiber $(1.2 / 100 \mathrm{~g}), 13.6 \%$ crude protein, quality protein (8-19\%), $63.2 \%$ starch, $\alpha$-amylase activity, minerals (2.3 $\mathrm{mg} / 100 \mathrm{~g}$ ), vitamins $\mathrm{A}$ and $\mathrm{B}$, and antioxidants such as coumaric acids and ferulic acid (Goswami et al., 2020). In addition, it is rich in unsaturated fatty acids (75\%) and phytic acid, which are considered to be useful in lowering cholesterol and phytate, which in turn reduces cancer risk. It also exhibits antioxidant activities due to the presence of polyphenols, anthocyanins, phytates, phytosterols, tannins and pinacosanols and thus plays a significant role in aging. It is also enriched with many essential amino acids except lysine and threonine and has relatively higher methionine. Being gluten-free, it is extremely useful for people suffering from celiac diseases who are generally allergic to the gluten content of wheat and other cereals. Pearl 
TABLE 3 | Nutritional comparison of pearl millet with sorghum, rice, and wheat (in $100 \mathrm{~g}$ grain).

\begin{tabular}{lcccc}
\hline \multirow{2}{*}{ Contents } & \multicolumn{3}{c}{ Crop } \\
\cline { 2 - 5 } & Pearl millet & Sorghum & Rice & Wheat \\
\hline Carbohydrates (g) & 61.8 & 67.7 & 78.2 & 64.7 \\
Protein (g) & 10.9 & 09.9 & 07.9 & 10.6 \\
Fat (g) & 5.43 & 1.73 & 0.52 & 1.47 \\
Energy (Kcal) & 347 & 334 & 356 & 321 \\
Dietary fiber (g) & 11.5 & 10.2 & 02.8 & 11.2 \\
Calcium (mg) & 27.4 & 27.6 & 07.5 & 39.4 \\
Phosphorus (mg) & 289 & 274 & 96 & 315 \\
Magnesium (mg) & 124 & 133 & 19 & 125 \\
Zinc (mg) & 2.7 & 1.9 & 1.2 & 2.8 \\
Fe (mg) & 6.4 & 3.9 & 0.6 & 3.9 \\
Thiamine (mg) & 0.25 & 0.35 & 0.05 & 0.46 \\
Riboflavin (mg) & 0.20 & 0.14 & 0.05 & 0.15 \\
Niacin (mg) & 0.9 & 2.1 & 1.7 & 2.7 \\
Folic acid ( $\mu \mathrm{g})$ & 36.1 & 39.4 & 9.32 & 30.1 \\
\hline
\end{tabular}

Adapted from: NIN, Hyderabad, 2018.

millet is exceptionally useful for people suffering from diseases like diabetes, obesity, diabetic heart disease, atherosclerosis and metabolic diseases due to its health beneficial properties (Kumar et al., 2020).

It is also called the "Powerhouse of Nutrition" due to its richness with essential nutrients in good quantity and quality, which are vital for leading healthy and nutritious life. Pearl millet has elevated contents of various macronutrients as well as micronutrients like iron, zinc, magnesium, calcium, phosphorous, copper, manganese, riboflavin, and folic acid. Owing to such excellent nutritional values, it is gaining popularity and is preferred by people all over the world including developed countries.

Despite its nutritional superiority, the consumption of pearl millet flour is restricted to very few specific regions of the world because of the poor shelf life of the flour and the development of rancidity or off-odor on storage (Rani et al., 2018). Rancidity is caused by oxidative/hydrolytic enzymes such as lipase, lipoxygenase (LOX), etc., where they hydrolyze the triacylglycerol (TAG) to diacylglycerols, glycerol, monoglycerol, and free fatty acids (Manley and Mayer, 2012) (Figure 4).

Goswami et al. (2020) categorized 93 diverse genotypes of pearl millet into low, medium and high rancid groups. They developed and validated a rancidity matrix (RM) having three groups and six classes, which can prove very useful for the pearl millet breeders to develop low rancid pearl millet lines (Figure 5).

Pearl millet is used in different forms at a global level: unleavened bread (roti or chapatti), porridge, gruel, dessert etc. and it is generally defined as a poor man's bread. Its flour can substitute (10-20\%) for wheat flour in "whole-grain" breads, pretzels, crackers, tortillas and dry and creamed cereals (Dahlberg et al., 2003). In India and Africa, it is primarily grown for food and forage, while in the American continents, it is a main component of poultry and livestock sector (Serba et al., 2020).
Value addition is also very useful to promote its consumption, and several value-added products are gaining popularity among people. It can be used for making various traditional food products such as khichri, roti, sakarpare, gulgule etc., while industries are also using it for making products such as noodles, pasta, vermicelli, biscuits, bread, cookies, cakes, puffs etc in India (Figure 6). Several indigenous foods and drinks are made from flour/meal and malt of the millet in Africa and are nutritionally superior to other cereals. They contain high protein (up to 9.5/100 g for teff and fonio), ash, calcium (up to $344 \mathrm{mg} / 100 \mathrm{~g}$ for finger millet), phosphorus and potassium (up to $250 \mathrm{mg} / 100 \mathrm{~g}$ ), iron and zinc levels (Obilana and Manyasa, 2002). The main food items prepared from pearl millet vary in the different countries of West Africa. The stiff or thick porridges (Tuwo or Tộ) are very famous and generally used in all the Sahelian countries, while steam-cooked product "Couscous" is more common in the Francophone countries, including Senegal, Mali, Guinea, Burkina Faso, Niger, and Chad. The thin porridge "bouillie" is also popular in these countries. In Nigeria and Niger, the thin porridge "Fourra" and Masa, a fried cake are very popular, while "Soungouf," "Sankhal" and "Araw" are mainly popular in Senegal (Kaur et al., 2014; Ajeigbe et al., 2020). Its grains are also locally brewed to produce non-alcoholic or alcoholic beverages in Asia and Africa (Dwivedi et al., 2012).

Among the 26 major risk factors for the disease estimates at the global level, Fe deficiency positions at ninth and $\mathrm{Zn}$ deficiency falls at $11^{\text {th }}$ position (Ezzati et al., 2002). This issue is mainly severe in developing countries and infants, pregnant women, and adolescent children are particularly among highrisk groups. In India, 80\% pregnant women, 52\% non-pregnant women and $74 \%$ of children lying in the age group of 635 months are suffering from anemia caused by Fe deficiency (Kramer and Allen, 2015). On the other hand, 50\% of the world population is affected by zinc $(\mathrm{Zn})$ deficiency, ultimately leading to diarrhea, impaired physical growth, and suppressed immune system (Gibson et al., 2008). In this context, biofortification of staple crops is a good, cost-effective, and sustainable approach to address malnutrition caused by micronutrients (Stein et al., 2007; Bouis et al., 2011). Biofortification is a multidisciplinary approach that can utilize the full potential of crop improvement and nutrition science and eliminate the prolonged issue of micronutrient malnutrition. Recent study showed that consuming biofortified pearl millet at $250 \mathrm{~g} \mathrm{day}^{-1}$ can meet $84 \%$ of the RDA for iron and $100 \%$ of the RDA for zinc in non-pregnant non-lactating (NPNL) women, while ordinary pearl millet can fulfill only $20 \%$ of their iron requirement (Neeraja et al., 2017). Absorption or bioavailability of iron in pearl millet is enough to meet out $>50 \%$ of the daily requirement of adult males or children. In pearl millet, the bioavailability of Fe can be assumed to be 7.0-7.5\% (Govindaraj et al., 2019). Approximately $50-100 \%$ of the daily requirement of iron can be met out with one meal of biofortified high-iron variety and is sufficient enough to overcome deficiency of iron in children, women and men (Kodkany et al., 2013; Mahendrakar et al., 2019).

Pearl millet as such is already a high-iron crop along with high $\mathrm{Zn}$ content; however, commercially available cultivars have lower Fe and $\mathrm{Zn}$ contents. Biofortification priority index (BPI) 

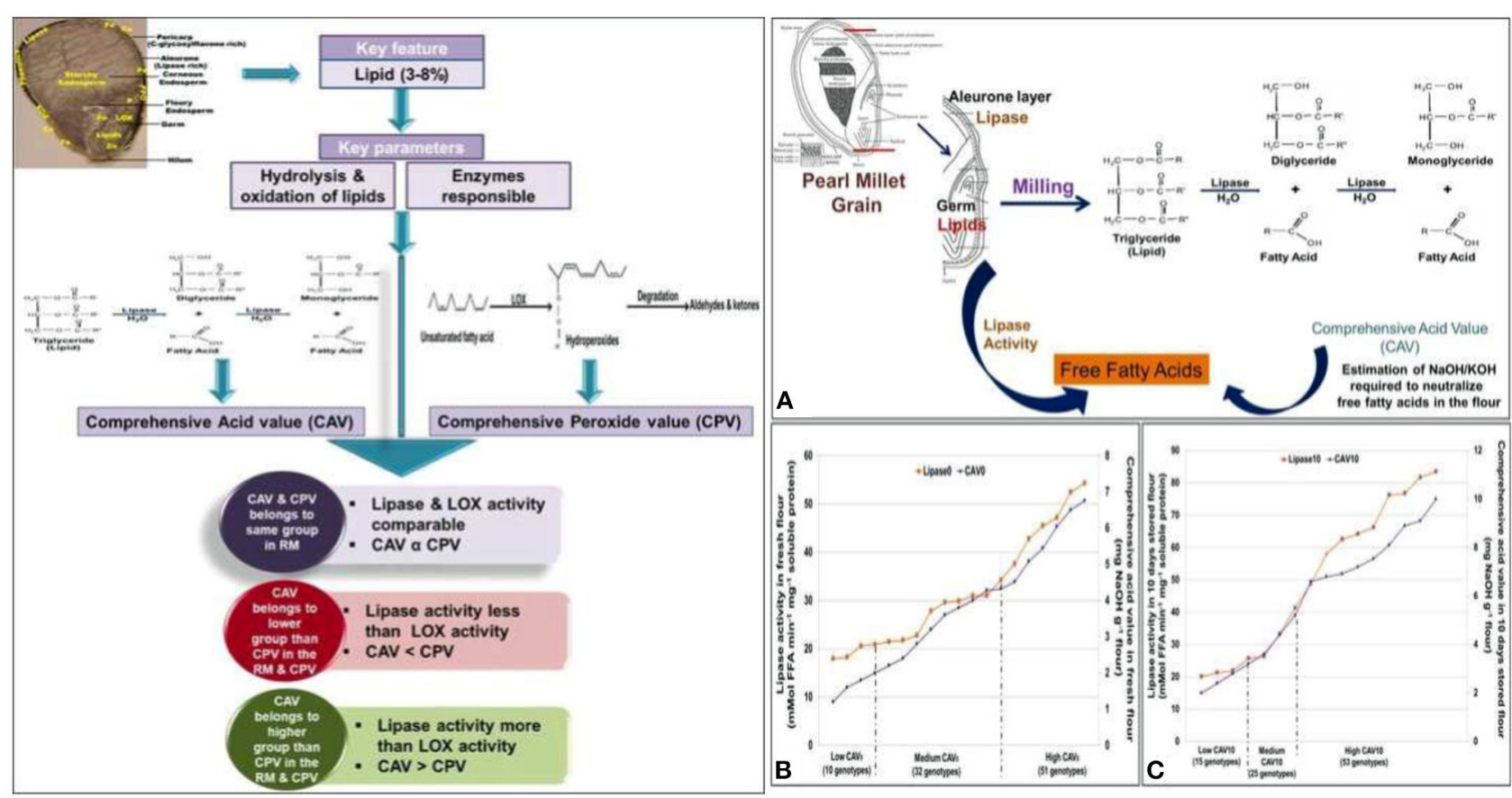

FIGURE 4 | Mechanism of action and role of lipase activity for shelf life in pearl millet flour (Adapted from: Goswami et al., 2020). (A) Correlation between lipase activity and comprehensive acid value (CAV). (B) Correlating the lipase activity and CAV of pearl millet genotypes in group I (freshly milled flour). (C) Correlating the lipase activity and CAV of pearl millet genotypes in group II (10-day stored flour).

indicates that pearl millet is a major target crop for iron and zinc biofortification. Enormous genetic variability (30-140 $\mathrm{mg} / \mathrm{kg} \mathrm{Fe}$ and $20-90 \mathrm{mg} / \mathrm{kg} \mathrm{Zn}$ ) can be used efficiently for developing high-yielding cultivars along with high iron and zinc densities (Kanatti et al., 2014). Targeting the development of biofortified crops with enhanced nutrients, ICAR is supporting a Consortia Research Platform (CRP) of rice, wheat, maize, sorghum, pearl millet and small millets since 2014. Several promising donors have been identified and breeding material is being generated combining high nutrient content and yield. Thus, focus was also laid on nutritional improvement in addition to yield improvement in pearl millet. Development of Fe and $\mathrm{Zn}$ biofortified varieties/hybrids was considered as a high-priority area in pearl millet resulting in the inclusion of biofortification in the main stream and now it is a routine affair. The gradual shift of efforts of biofortification research from exploring variability in 2008 to breeding high-Fe cultivars by exploiting existing high-Fe lines in 2011 and testing and delivery of biofortified varieties and hybrids was recognized in India and became conscious breeding part in pearl millet at various centers of public and private partners. The first high-iron pearl millet variety "Dhanashakti" was released for the state of Maharashtra in 2013, and subsequently, it was notified and released by Central Variety Releasing Committee in April 2014, for growing in all pearl millet-growing regions of India. Inclusion of nutritional quality traits for $\mathrm{Fe}(42 \mathrm{ppm})$ and $\mathrm{Zn}(32 \mathrm{ppm})$ in the varietal promotion criteria is first of its kind in any of the food crop and the world too (Satyavathi, 2017). Since then, many hybrids/varieties were developed as micronutrient-rich pearl millet cultivars, including the seven biofortified cultivars identified from the special biofortification trial. In addition, a project on "Development of Biochemical and Physical Processing Technology to Arrest Oxidation of Lipids/Flavones to Enhance the Shelf-Life of Pearl Millet Flour" under Niche area of excellence (NAE) program has been started in ICAR-IARI, India, to overcome the issue of rancidity and enhance shelf life of pearl millet flour. Parallel research programs addressing the issues of rancidity were also taken up in ICRISAT along with ICAR.

Screening of enormous genetic materials such as germplasm collections, elite lines, hybrids, segregating populations etc. as well as phenotyping for iron and zinc through destructive techniques and breeding resources is required to breed micronutrient dense cultivars. Several studies have been conducted by several research groups around the world to assess the genetic diversity for $\mathrm{Fe}$ and $\mathrm{Zn}$ contents from time to time using different sets of germplasm accessions and breeding lines (Velu et al., 2007; Rai et al., 2012, 2014; Kanatti et al., 2014; Anuradha et al., 2017; Kumar et al., 2018; Govindaraj et al., 2019, 2020). Various studies were reported to show a significant importance of environment and $\mathrm{G} \times \mathrm{E}$ interactions to determine the levels of grain $\mathrm{Fe}$ and grain $\mathrm{Zn}$ contents in pearl millet. Such studies also identified donors that are high and stable micronutrient contents (Satyavathi et al., 2015; Rai et al., 2016; Pawar et al., 2018; Singhal et al., 2018). In addition, many efforts were put to discover, validate and deploy trait-based molecular markers for iron and zinc contents in pearl millet 


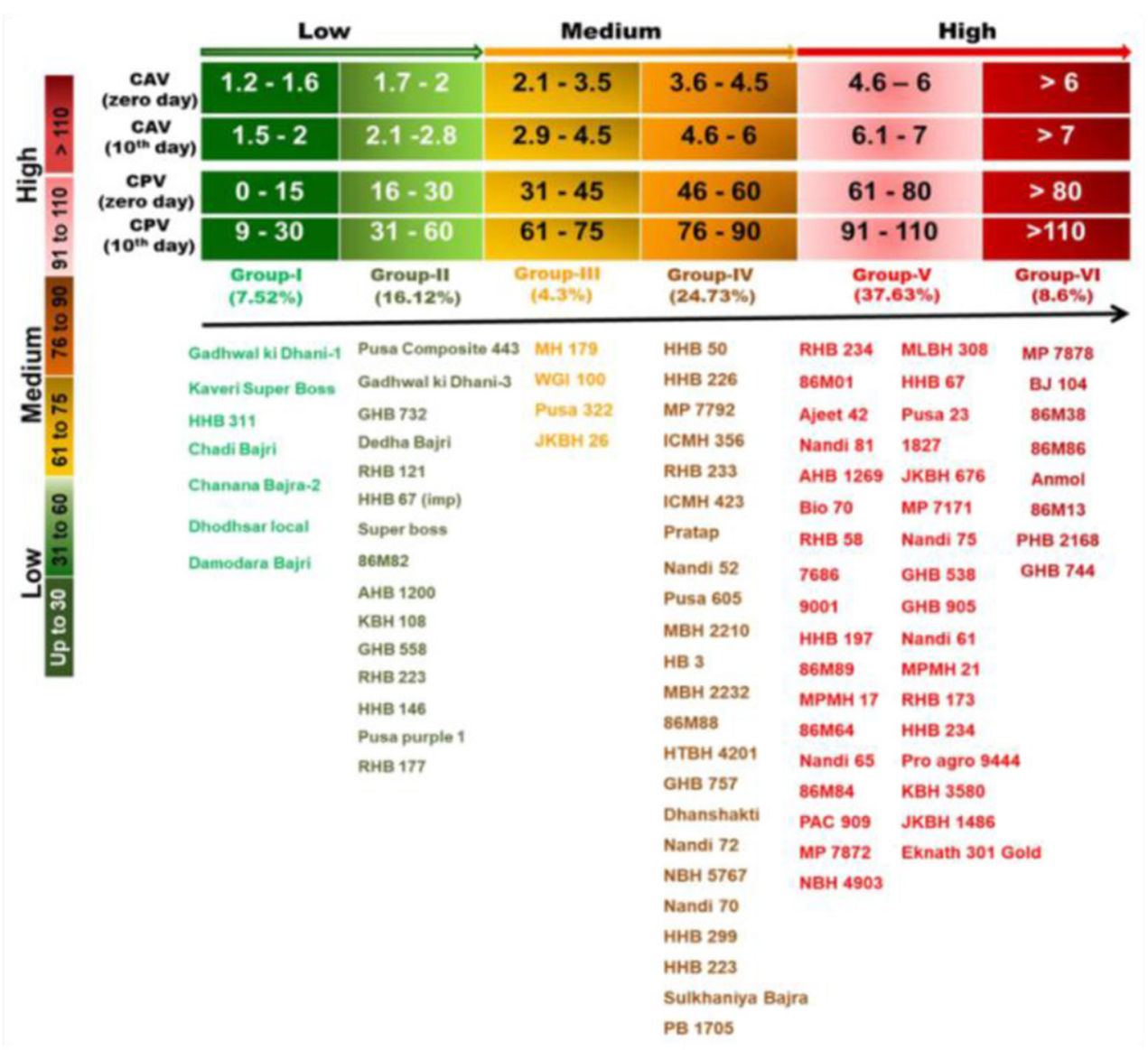

FIGURE 5 | Rancidity matrix to measure rancidity in the pearl millet flour (Adapted from: Goswami et al., 2020).

\section{Products}

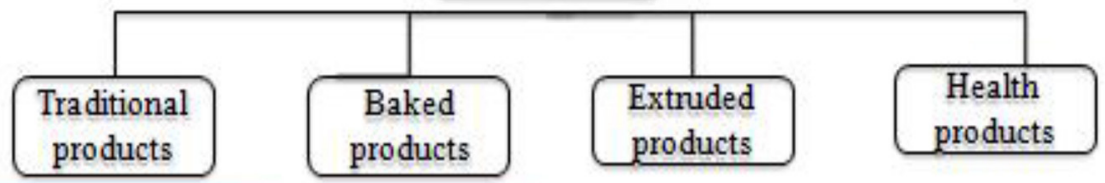

Roti, rabbri, dalia,
kheer, churma, suhali,
khichri, mathi, sev,
ladoo, barfi,pakoda,
dhokla etc.

Biscuit, bread,

cake,nan-

khatai, muffin
Pasta, vermicelli,

macroni
Sugarfree

biscuits, idli
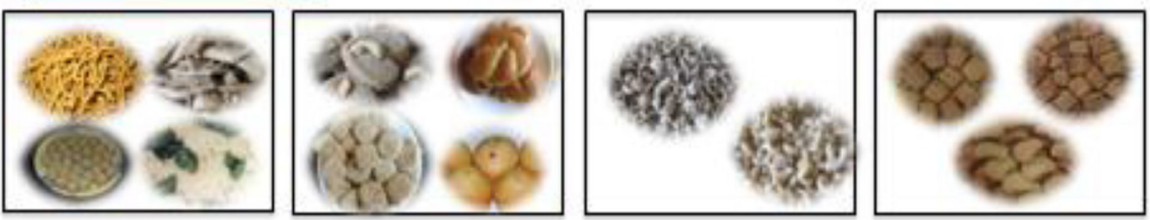

FIGURE 6 | Delicious and value-added food products from pearl millet. 


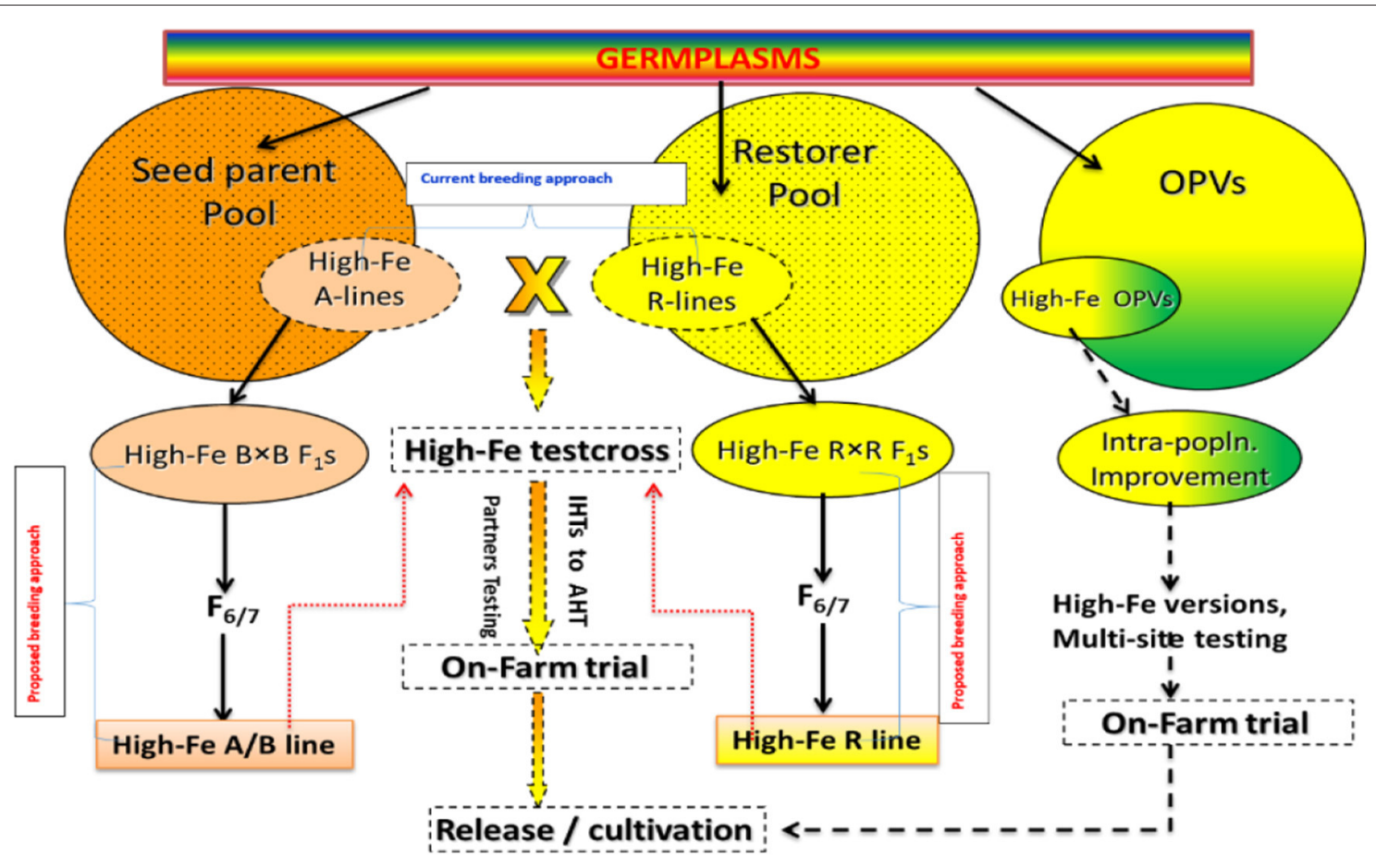

FIGURE 7 | Current breeding approaches followed for developing biofortified cultivars in pearl millet (Adapted from: Govindaraj et al., 2019).

(Kumar et al., 2016, 2018; Anuradha et al., 2017). Manwaring et al. (2016) elaborated the several challenges and opportunities associated with biofortification of pearl millet and emphasized that naturally occurring genetic variations existing in germplasm collections should be incorporated into elite, micronutrientrich varieties through different advanced platforms to develop bifortified varieties.

The success of pearl millet biofortification program lies in the high-throughput precision phenotyping for the estimation of grain micronutrient content. Further, demonstration of the feasibility of developing high-Fe and high-yielding hybrids and encouraging the partners to breed for these micronutrient traits by means of mainstreaming the biofortification can be an important approach for its promotion. There is a high need to facilitate the focused screening of partners breeding materials for grain $\mathrm{Fe}$ and $\mathrm{Zn}$ contents for their introgression of high $\mathrm{Fe}$ content into locally adapted, high-yielding and farmer-preferred cultivars (Figure 7). Promotion and strengthening of the pipeline of high-iron and high-yielding partners-bred hybrids and testing of their grain samples for grain $\mathrm{Fe}$ and $\mathrm{Zn}$ contents can be a useful step for enhancing its importance. In addition to this, bioavailability is another aspect that needs to be focused to get full potential of this crop.

\section{CHALLENGES FOR PEARL MILLET}

Despite the breeding efforts, most of breeding programs fail to deliver hybrids due to a vast variation in microclimate (day and night temperature and humidity) and soil apart from rainfall, which requires proper quantification. Further, narrow cultivar diversity in drought-prone ecology also is another factor for this. Thus, there is a high need to give higher priority to the belowmentioned areas to promote its production and utilization:

- Development of hybrids/varieties of pearl millet with better regenerative capacity on reversal of dry spell for harsh environment/drought-prone areas (for $\mathrm{A}_{1}$ zone in India).

- Development of hybrids/varieties resistant/tolerant to salt/high temperature.

- Shift in focus of breeding from productivity improvement to the identification of end product-specific traits.

- Mainstreaming of biofortification in pearl millet for iron and zinc.

- Enhancement of shelf life of pearl millet flour and overcome rancidity to promote its products.

- Development of screening protocols and control measures against different diseases such as downy mildew, blast, rust, ergot, smut.

- Generating authentic data on nutritional benefits of pearl millet and bioavailability studies.

- A study on demand survey for pearl millet.

\section{CONCLUSION}

Pearl millet being a climate-resilient crop along with high nutritional value can be exploited for improving nutritional quality and combating malnutrition. It is almost free from major diseases and insect attacks and could be cultivated with a good harvest. Hence, the focus should be laid towards the development of food products from pearl millet to make 
it acceptable as an alternative crop of the future. Indian policymakers need to refocus their interest toward millet farming systems and policies should be engraved for creating a feasible environment for pearl millet farmers. After the successful use of genomic tools, screening and development of improved genotypes have become easy and fast, and the progress toward enhancing the use of genomic resources is quite appreciable. But it can be characterized further for harnessing the natural genetic variation within the germplasm, and a lot of efforts are still required to execute genomics to improve the crop using high-throughput genome analysis, sequence-based molecular markers, NGS techniques and genome editing etc. The genomics and breeding platform needs a better alignment and constant up-gradation to develop improved hybrid parental lines, and populations must be adapted specifically according to the specific global agro-ecologies. The idea of genetic gains, genome editing, pre-breeding, and speed breeding can be also very useful for the researchers in selecting plants for desired traits along with many variations. On the other hand, the construction of high-density maps, QTL detection, candidate gene identification, new genome sequence techniques, use of advanced multi-parental and AM panels, GWAS and GS can speed up the recognition of allelic variants for pearl millet improvement. Mapping of several abiotic stresses, QTLs, etc. is highly desired to combat global climatic effects and the recently developed technologies must be tested under actual conditions.

The outcomes from model crops can be used in pearl millet to achieve added improvement and develop $\mathrm{Zn}$ - and $\mathrm{Fe}-$ enriched biofortified varieties. Synteny studies can prove useful for the identification of common genes linked with nutrition

\section{REFERENCES}

Agarwal, P., Agarwal, P. K., Joshi, A. J., Sopory, S. K., and Reddy, M. K. (2010). Overexpression of PgDREB2A transcription factor enhances abiotic stress tolerance and activates downstream stress-responsive genes. Mol. Biol. Rep. 37, 1125-1135. doi: 10.1007/s11033-009-9885-8

Ajeigbe, H. A., Angarawai, I. I., Inuwa, A. H., Akinseye, F. M., and Abdul Azeez, T. (2020). Hand Book on Improved Pearl Millet Production Practices in North Eastern Nigeria, 9885-9888.

Allouis, S., Qi, X., Lindup, S., Gale, M. D., and Devos, K. M. (2001). Construction of a BAC library of pearl millet, Pennisetum glaucum. Theor. Appl. Genet. 102, 1200-1205. doi: 10.1007/s001220100559

Ambawat, S., Senthivel, S., Hash, C. T., Nepolean, T., Rajaram, V., Eshwar, K., et al. (2016). QTL mapping for rust resistance in pearl millet using an integrated DArT and SSR-based linkage map. Euphytica. 209, 461-476. doi: 10.1007/ s10681-016-1671-9

Ambawat, S., Singh, S., Shobhit, Meena R. C., and Satyavathi, C.T. (2020). "Biotechnological applications for improvement of the pearl millet crop." in: Pearl Millet: Properties, Functionality and its Applications, eds S. K. Gahlawat, S. Punia, A. K. Siroha, K. S. Sandhu, and M. Kaur (Boca Raton, FL: Taylorand Francis (CRC Press)), 115-138.

Anuradha, N., Satyavathi, C.T., Meena, M. C., Sankar, S. M., Bharadwaj, C., Bhat, J., et al. (2017). Evaluation of pearl millet [Pennisetum glaucum (L.) R. Br.] for grain iron and zinc content in different agro climatic zones of India. Indian J. Genet. Plant Breed. 77, 65-73. doi: 10.5958/0975-6906.2017.00009.8

Aparna, K., Nepolean, T., Srivastsava, R. K., Kholová, J., Rajaram, V., Kumar, S., et al. (2015). Quantitative trait loci associated with constitutive traits control water use in pearl millet [Pennisetum glaucum (L.) R. Br.]. Plant Biol. 17, 1073-1084. doi: 10.1111/plb.12343

Athwal, D. S. (1965). Hybrid bajara-1 marks a new era. Indian Farm. 15,6-7. biosynthesis pathways, and these should be incorporated into pearl millet by traditional breeding or transgene techniques for further nutritional improvements. In addition, nutritional as well as the economic security of small and marginal farmers, enhancing demand of pearl millet, value addition and marketled extension through food science and nutrition is vital to promote the cultivation and consumption of this crop. In conclusion, multidisciplinary approaches, including breeding, genomics, bioinformatics, biotechnology, nutrition and genetics etc. are required to exploit and harness the beneficial attributes of nutricereal pearl millet for combating changing climate and attaining nutritional security.

\section{AUTHOR CONTRIBUTIONS}

CTS has conceived the idea of writing this review, drafted and edited the manuscript. SA contributed in writing and editing the manuscript. RKS and VK contributed in manuscript preparation.

\section{ACKNOWLEDGMENTS}

We sincerely acknowledge Indian Council of Agricultural Research (ICAR), New Delhi for providing financial assistance under ICAR-All India Coordinated Research Project on Pearl millet, Jodhpur (AICRP on Pearl millet).

\section{SUPPLEMENTARY MATERIAL}

The Supplementary Material for this article can be found online at: https://www.frontiersin.org/articles/10.3389/fpls.2021. 659938/full\#supplementary-material

Bertin, I., Zhu, J. H., and Gale, M. D. (2005). SSCP-SNP in pearl millet-a new marker system for comparative genetics. Theor. Appl. Genet. 110, 1467-1472. doi: 10.1007/s00122-005-1981-0

Bhattacharjee, R., Bramel, J., Hash, T., Kolesnikova-Allen, A., and Khairwal, S. (2002). Assessment of genetic diversity within and between pearl millet landraces. Theor. Appl. Genet. 105, 666-673. doi: 10.1007/s00122-0020917-1

Bidinger, F. R., Nepolean, T., Hash, C. T., Yadav, R. S., and Howarth, C. J. (2007). Quantitative trait loci for grain yield in pearl millet under variable post flowering moisture conditions. Crop Sci. 47, 969-980. doi: 10.2135/cropsci2006.07.0465

Bidinger, F. R., Serraj, R., Rizvi, S. M. H., Howarth, C. J., Yadav, R. S., and Hash, C. T. (2005). Field evaluation of drought tolerance QTL effects on phenotype and adaptation in pearl millet [Pennisetum glaucum (L.) R. Br.] topcross hybrids. Field Crops Res. 94, 14-32. doi: 10.1016/j.fcr.2004.11.006

Bollam, S., Pujarula, V., Srivastava, R. K., and Gupta, R. (2018). "Genomic approaches to enhance stress tolerance for productivity improvements in pearl millet: genomic approaches". in Biotechnologies of Crop Improvement, Vol. 3, eds. S. S. Gosal and S. H. Wani. (Basel: Springer International Publishing AG, part of Springer Nature), 239-264.

Bouis, H. E., Hotz, C., Mc Clafferty, B., Meenakshim, J.V., and Pfeiffer, W. H. (2011). Biofortification: a new tool to reduce micronutrient malnutrition. Food Nutr. Bull. 32, S31-S40. doi: 10.1177/15648265110321S105

Bray, E. A., Bailey-Serres, J., and Weretilnyk, E. (2000). "Responses to abiotic stresses." in Biochemistry and Molecular Biology of Plants, eds W. Gruissem, B. Buchannan, R. Jones (Rockville, MD: American Society of Plant Physiologists), 1158-1249.

Breese,W. A., Hash, C. T., Devos, K. M., and Howarth, C. J., Leslie, J. F. (2002). Pearl millet genomics and breeding for resistance to downy mildew. Sorghum Millets Dis. 243-246. doi: 10.1002/9780470384923.ch41 
Budak, H., Pedraza, F., Cregan, P. B., Baenziger, P. S., and Dweikat, I. (2003). Development and utilization of SSRs to estimate the degree of genetic relationships in a collection of pearl millet germplasm. Crop Sci. 43:2284. doi: $10.2135 /$ cropsci2003.2284

Busso, C. S., Devos, K. M., Ross, G., Mortimore, M., Adams, W. M., Ambrose, M. J., et al. (2000). Genetic diversity within and among landraces of pearl millet (Pennisetum glaucum) under farmer management in West Africa. Genet. Res. Crop Evol. 47, 561-8. doi: 10.1023/A:1008767220320

Chandra, S., Singh, S. P., Kaswan, V., Chaudhary, S., Singh, A. M., Sankar, M., et al. (2020). Morphological and molecular genetic diversity analysis of pearl millet (Pennisetum glaucum) maintainers and restorers. Indian J. Agric. Sci. 90, 2083-2089

Chelpuri, D., Sharma, R., Durga, K. K., Katiyar, P., Mahendrakar, M. D., Singh, R. B., et al. (2019). Mapping quantitative trait loci (QTLs) associated with resistance to major pathotype-isolates of pearl millet downy mildew pathogen. Eur. J. Plant Pathol. 154, 983-994. doi: 10.1007/s10658-019-01718-x

Choudhary, S., Guha, A., Kholova, J., Pandravada, A., Essina, C. D., Cooper, M., et al. (2020). Maize, sorghum, and pearl millet have highly contrasting species strategies to adapt to water stress and climate change-like conditions. Plant Sci. 295:110297. doi: 10.1016/j.plantsci.2019.110297

Dahlberg, J. A., Wilson, J. P., and Snyder, T. (2003). "Sorghum and pearlmillet: health foods and industrial products in developed countries." in Alternative Uses of Sorghum and Pearl Millet in Asia. Proceedings of Expert Meeting (Patancheru: ICRISAT). 42-59.

Datta Mazumdar, S. K., Gupta, R., Banerjee, S., Gite, P., and Durgalla, P. B. (2016). Determination of Variability in Rancidity Profile of Select Commercial Pearl Millet Varieties/Hybrids. DC 24. Poster presented in CGIAR Research Program on Dryland Cereals Review Meeting held at Hyderabad, India, 5-6 October 2016. International Crops Research Institute for the Semi-Arid Tropics, Patancheru, Telangana, India. Available online at: http://drylandcereals.cgiar. org/index.php

Debieu, M., Sine, B., Passot, S., Grondin, A., Akata, E., Gangashetty, P., et al. (2018). Response to early drought stress and identification of QTLs controlling biomass production under drought in pearl millet. PLoS ONE. 13:e201635. doi: 10.1371/journal.pone.0201635

Desai, M. K., Mishra, R. N., Verma, D., Nair, S., Sopory, S. K., and Reddy, M. K. (2006). Structural and functional analysis of a salt stress inducible gene encoding voltage dependent anion channel (VDAC) from pearl millet (Pennisetumglaucum). Plant Physiol. Biochem. 44, 483-493. doi: 10.1016/j.plaphy.2006.08.008

Devos, K. M., Pittaway, T. S., Busso, C. S., Gale, M. D., Witcombe, J. R., and Hash, C. T. (1995). Molecular tools for the pearl millet nuclear genome. Int. Sorghum Millets Newslett. 36, 64-66.

Diack, O., Kanfany, G., Gueye, M. C., Sy, O., Fofana, A., Tall, H. et al. (2020). GWAS unveils features between early- and late-flowering pearl millets. BMC Genomics. 21:777. doi: 10.1186/s12864-020-07198-2

Directorate of Millets Development (2020). Department of Agriculture, Cooperation \& Farmers Welfare, Ministry of Agriculture \& Farmers Welfare, Government of India.

Dita, M. A., Rispail, N., Prats, E., Rubiales, D., and Singh, K. B. (2006). Biotechnology approaches to overcome biotic and abiotic stress constraints in legumes. Euphytica. 147, 1-24. doi: 10.1007/s10681-006-6156-9

Dudhate, A., Shinde, H., Tsugama, D., Liu, S., and Takano, T. (2018). Transcriptomic analysis reveals the differentially expressed genes and pathways involved in drought tolerance in pearl millet [Pennisetum glaucum (L.) R. Br]. PLoS ONE. 13:e0195908. doi: 10.1371/journal.pone.0195908

Dwivedi, S., Upadhyaya, H., Senthilvel, S., and Hash, C. (2012). "Millets: genetic, and genomic resources," in Plant Breeding Reviews, ed. J. Janick (Hoboken, NJ: John Wiley, and Sons, Inc.), 247-375.

Dyall, S. C. (2015). Long-chain omega-3 fatty acids and the brain: a review of the independent and shared effects of EPA, DPA and DHA. Front. Aging Neurosci. 7:52. doi: 10.3389/fnagi.2015.00052

Ezzati, M., Lopez, A. D., Rodgers, A., Vanderhoorn, S., and Murray, C. J. L. (2002). Selected major risk factors and global and regional burden of disease. Lancet. 360, 1347-1360. doi: 10.1016/S0140-6736(02)11403-6

FAO (2019). Food and Agriculture Organization of the United Nations. Rome.

Ghatak, A., Chaturvedi, P., Bachmann, G., Valledor, L., Ramšak, Ž., Bazargani, M. M., et al. (2021). Physiological and proteomic signatures reveal mechanisms of superior drought resilience in pearl millet compared to wheat. Front. Plant Sci. 11:600278. doi: 10.3389/fpls.2020.600278

Ghatak, A., Chaturvedi, P., Nagler, M., Roustan, V., Lyon, D., Bachmann, G., et al. (2016). Comprehensive tissue-specific proteome analysis of drought stress responses in Pennisetum glaucum (L.) R. Br. (Pearl millet). J. Proteomics. 143, 122-135. doi: 10.1016/j.jprot.2016.02.032

Ghatak, A., Chaturvedi, P., and Weckwerth, W. (2017). Cereal crop proteomics: systemic analysis of crop drought stress responses towards marker-assisted selection breeding. Front. Plant Sci. 8:757. doi: 10.3389/fpls.2017.00757

Gibson, R. S., Hess, S. Y., Hotz, C., and Brown, K. H. (2008). Indicators of zinc status at the population level: a review of the evidence. Br. J. Nutr. 99, S14-S23. doi: $10.1017 /$ S0007114508006818

Goddard, M. E., and Hayes, B. J. (2007). Genomic selection. J. Anim. Breed. Genet. 124, 323-330. doi: 10.1111/j.1439-0388.2007.00702.x

Goswami, S., Asrani, P., Ansheef Ali, T.P., Kumar, R. D., Vinutha, T., Veda, K. et al. (2020). Rancidity matrix: development of biochemical indicators for analysing the keeping quality of pearl millet flour. Food Anal. Meth. 13, 2147-2164. doi: 10.1007/s12161-020-01831-2

Govindaraj, M., Rai, K. N., Cherian, B., Pfeiffer, W. H., Kanatti, A., and Shivade, H. (2019). Breeding biofortified pearl millet varieties and hybrids to enhance millet markets for human nutrition. Agriculture. 9:106. doi: 10.3390/agriculture9050106

Govindaraj, M., Selvi, B., and Rajarathinam, S. (2009). Correlation studies for grain yield components and nutritional quality traits in pearl millet (Pennisetum glaucum (L.) R. Br.) Germplasm. World J. Agric. Sci. 5, 686-689.

Govindaraj, M., Shanmugasundaram, P., Sumathi, P., and Muthiah, A. R. (2010). Simple, rapid and cost effective screening method for drought resistant breeding in pearl millet. Elec J Plant Breed. 1, 590-599.

Govindaraj, M., Yadav, O. P., Rajpurohit, B. S., Kanatti, A., Rai, K. N., and Dwivedi, S. L. (2020). Genetic variability, diversity and interrelationship for twelve grain minerals in 122 commercial pearl millet cultivars in India. Agric. Res. 9, 516-525. doi: 10.1007/s40003-020-00470-7

Goyal, P., and Chugh, L. K. (2017). Shelf life determinants and enzyme activities of pearl millet: a comparison of changes in stored flour of hybrids, CMS lines, inbreeds and composites. J. Food Sci. Technol. 54, 3161-3169. doi: 10.1007/s13197-017-2752-z

Gulia, S. K., Hash, C. T., Thakur, R. P., Breese, W. A., and Sangwan, R. S. (2007) "Mapping new QTLs for downy mildew [Sclerospora graminicola (Sacc.) J. Schroet.] resistance in pearl millet [Pennisetum glaucum (L.) R. Br.”.] in Crop Production in Stress Environments - Genetic and Management Options, eds D. S. Singh, V. S. Tomar, R. K. Behl, S. D. Upadhyaya, and M. S. Bhale (New Delhi: Agrobios International).

Gupta, S. K., Rai, K. N., Singh, P., Ameta, V. L., Gupta, S. K., Jayalekha, A. K., et al. (2015). Seed set variability underhigh temperatures during flowering period in pearl millet [Pennisetum glaucum L. (R.) Br.]. Field Crops Res. 171, 41-53. doi: 10.1016/j.fcr.2014.11.005

Gupta, S. K., Sudarshan Patil, K., Rathore, A., Yadav, D. V., Sharma, L. D. Mungra, K. D., et al. (2020). Identification of heterotic groups in SouthAsian-bred hybrid parents of pearl millet. Theor. Appl. Genet. 133, 873-888. doi: 10.1007/s00122-019-03512-Z

Hash, C. T., Singh, S. D., Thakur, R. P., and Talukdar, B. S. (1999). "Breeding for disease resistance”. in Pearl Millet Breeding, eds I. S. Khairwal, K. N. Rai, D. J. Andrews, G. Harinarayana (New Delhi: Oxford and IBH), 337-379.

Hash, C. T., Thakur, R. P., Rao, V. P., and Raj, A. B. (2006). Evidence for enhanced resistance to diverse isolates of pearl millet downy mildew through gene pyramiding. Int. Sorghum Millets Newsl. 47, 134-138.

Hash, C. T., and Witcombe, J. R. (2002). "Gene management and breeding for downy mildew resistance". in: Sorghum and Millets Diseases, ed J. E. Leslie (Ames, IA: Iowa State Press), 27-36.

Heffner, E. L., Sorrells, M. E., and Jannink, J. L. (2009). Genomic selection for crop improvement. Crop Sci. 49, 1-12. doi: 10.2135/cropsci2008.08.0512

Hrdlickova, R., Toloue, M., and Tian, B. (2017). RNA-Seq methods for transcriptome analysis. Wiley Inter. Discip. Rev. RNA. 8:e1364, doi: 10.1002/wrna.1364

Hu, Z., Mbacké, B., Perumal, R., Guèye, M. C., Sy, O., Bouchet, S., et al. (2015). Population genomics of pearl millet (Pennisetum glaucum (L.) R. $\mathrm{Br}$.): comparative analysis of global accessions and Senegalese landraces. BMC Genomics. 16:1048. doi: 10.1186/s12864-015-2255-0 
Jaiswal, S., Antala, T. J., Mandavia, M. K., Chopra, M., Jasrotia, R. S., Tomar, R. S., et al. (2018). Transcriptomic signature of drought response in pearl millet (Pennisetum glaucum (L.) and development of web-genomic resources. Sci. Rep. 8, 1-16. doi: 10.1038/s41598-018-21560-1

Jangra, S., Rani, A., Yadav, R. C., Yadav, N. R., and Yadav, D. (2019). Introgression of terminal drought stress tolerance in advance lines of popular pearl millet hybrid through molecular breeding. Plant Physiol. Rep. 24, 359-369. doi: 10.1007/s40502-019-00464-w

Jarquin, D., Howard, R., Liang, Z., Gupta, S. K., Schnable, J. C., and Crossa, J. (2019). Enhancing hybrid prediction in pearl millet using genomic and/or multi-environment phenotypic information of inbreds. Front. Genet. 10:e01294. doi: 10.3389/fgene.2019.01294

Jogaiah, S., Sharathchandra, R. G., and Raj, N. (2014). Development of SCAR marker associated with downy mildew disease resistance in pearl millet (Pennisetum glaucum L.). Mol. Biol. Rep. 41, 7815-7824. doi: 10.1007/s11033-014-3675-7

Jones, E. S., Breese, W. A., Liu, C. J., Singh, S. D., Shaw, D. S., and Witcombe, J. R. (2002). Mapping quantitative trait loci for resistance to downy mildew in pearl millet: field and glasshouse screens detect the same QTL. Crop Sci. 42, 1316-1323. doi: 10.2135/cropsci2002.1316

Jones, E. S., Liu, C. J., Gale, M. D., Hash, C. T., and Witcombe, J. R. (1995). Mapping quantitative trait loci for downy mildew resistance in pearl millet. Theor. Appl. Genet. 91, 448-456. doi: 10.1007/BF00222972

Jukanti, A. K., Gowda, C. L. L., Rai, K. N., Manga, V. K., and Bhatt, R. K. (2016). Crops that feed the world 11. Pearl millet (Pennisetum glaucum L.): an important source of food security, nutrition and health in the arid and semi-arid tropics. Food Sec. 8, 307-329. doi: 10.1007/s12571-016-0557-y

Kanatti, A., Rai, K. N., Radhika, K., and Govindaraj, M. (2016). Genetic architecture of open-pollinated varieties of pearl millet for grain iron and zinc densities. Indian J Genet. 76, 299-303. doi: 10.5958/0975-6906.2016.00045.6

Kanatti, A., Rai, K. N., Radhika, K., Govindaraj, M., Sahrawat, K. L., Srinivasu, K., et al. (2014). Relationship of grain iron and zinc content with grain yield in pearl millet hybrids. Crop Improv. 41, 91-96.

Kanfany, G., Serba, D. D., Rhodes, D., Amand, P., Bernardo, A., and Gangashetty, P. (2020). Genomic diversity in pearl millet inbred lines derived from landraces and improved varieties. BMC Genomics. 21:469. doi: 10.1186/s12864-020-06796-4

Kaur, K. D., Jha, A., Sabikhi, L., and Singh, A. K. (2014). Significance of coarsecereals in health and nutrition: a review. J. Food Sci. Technol. 51, 1429-1441. doi: 10.1007/s13197-011-0612-9

Kholová, J., Hash, C. T., Kakkera, A., Kočová, M., and Vadez, V. (2010). Constitutive water-conserving mechanisms are correlated with the terminal drought tolerance of pearl millet [Pennisetum glaucum (L.) R. Br.]. J. Exp. Bot. 61, 369-377. doi: 10.1093/jxb/erp314

Kholová, J., McLean, G., Vadez, V., Craufurd, P., and Hammer, G. L. (2013). Drought stress characterization of post-rainy season (rabi) sorghum in India. Field Crops Res. 141, 38-46.

Kholová, J., Nepolean, T., Hash, C. T., Supriya, A., Rajaram, V., Senthilvel, S., et al. (2012). Water saving traits co-map with a major terminal drought tolerance quantitative trait locus in pearl millet [Pennisetum glaucum (L.) R. Br.]. Mol Breed. 30, 1337-1353. doi: 10.1007/s11032-012-9720-0

Kodkany, B. S., Bellad, R. M., Mahantshetti, N. S., Westcott, J. E., Krebs, N. F., Kemp, J. F., et al. (2013). Biofortification of pearl millet with iron and zinc in a randomized controlled trial increases absorption of these minerals above physiologic requirements in young children. J. Nutr. 143, 1489-1493. doi: $10.3945 /$ jn.113.176677

Kramer, C. V., and Allen, S. (2015). Malnutrition in developing countries. Paediatr Child Health. 25, 422-427. doi: 10.1016/j.paed.2015.04.002

Krishnan, R., and Meera, M.S. (2018). Pearl millet minerals: effect of processing on bioaccessibility. J. Food Sci. Technol. 55, 3362-3372. doi: 10.1007/s13197-018-3305-9

Kulkarni, K. S., Zala, H. N., Bosamia, T. C., Shukla, Y. M., Kumar, S., Fougat, R. S., et al. (2016). De novo transcriptome sequencing to dissect candidate genes associated with pearl millet-downy mildew (Sclerospora graminicola Sacc.) interaction. Front. Plant Sci. 7:847. doi: 10.3389/fpls.2016.00847

Kumar, R. R., Rai, G. K., Goswami, S., Singh, S. P., Satyavathi, C. T., and Praveen, S. (2020). Millets the Orphan Crop for Uncertain Future. New Delhi: Scientific International Pvt. Ltd., 194.
Kumar, S., Hash, C., Nepolean, T., Mahendrakar, M., Satyavathi, C., Singh, G., et al. (2018). Mapping grain iron and zinc content quantitative trait loci in an iniadi-derived immortal population of pearl millet. Genes. 9:248. doi: 10.3390/genes 9050248

Kumar, S., Hash, C. T., Thirunavukkarasu, N., Singh, G., Rajaram, V., Rathore, A., et al. (2016). Mapping quantitative trait loci controlling high iron and zinc in self and open pollinated grains of pearl millet [Pennisetum glaucum (L) R. Br.]. Front. Plant Sci. 7:1636. doi: 10.3389/fpls.2016.01636

Kumara, C. D., Bantilan, C., Rajalaxmi, A., Rai, K. N., Yadav, O. P., Gupta, S. K., et al. (2014). Development and Diffusion of Pearl Millet Improved Cultivars in India: Impact on Growth and Yield Stability. Patancheru: ICRISAT.

Lata, C. (2015). Advances in omics for enhancing abiotic stress tolerance in millets. Proc. Indian Nat. Sci. Acad. 81, 397-417. doi: 10.16943/ptinsa/2015/v81i2/48095

Liang, Z., Gupta, S. K., Yeh, C. T., Zhang, Y., Ngu, D. W., Kumar, R., et al. (2018). Phenotypic data from inbred parents can improve genomic prediction in pearl millet hybrids. G3 Genes Genom. Genet. 8, 2513-2522. doi: $10.1534 / \mathrm{g} 3.118 .200242$

Liu, C. J., Witcombe, J. R., Pittaway, T. S., Nash, M., Hash, C. T., Busso, C. S., et al. (1994). An RFLP-based genetic map of pearl millet (Pennisetum glaucum). Theor. Appl. Genet. 89, 481-487. doi: 10.1007/BF00225384

Mahendrakar, M. D., Kumar, S., Singh, R. B., Rathore, A., Potupureddi, G., Kishor, P. K., et al. (2019). Genetic variability, genotype $\times$ environment interaction and correlation analysis for grain iron and zinc contents in recombinant inbred line population of pearl millet [Pennisetum glaucum (L). R. Br.]. Indian J. Genet. 79, 545-551. doi: 10.31742/IJGPB.79.3.3

Mahendrakar, M. D., Parveda, M., Kishor, P. K., and Srivastava, R. K. (2020). Discovery and validation of candidate genes for grain iron and zinc metabolism in pearl millet [Pennisetum glaucum (L.) R. Br.]. Sci. Rep. 10, 1-16. doi: 10.1038/s41598-020-73241-7

Manley, C., and Mayer, J. (2012). "Lipase," in Clinical Veterinary Advisor: Birds and Exotic Pets, eds J. Mayer and T. M. Donnelly (W. B. Saunders; Elseiver) doi: 10.1016/B978-1-4160-3969-3.00427-3

Manwaring, H. R., Bligh, H. F. J., and Yadav, R. (2016). The challenges and opportunities associated with biofortification of pearl millet (Pennisetum glaucum) with elevated levels of grain iron and zinc. Front. Plant Sci. 7:1944. doi: 10.3389/fpls.2016.01944

Meena, R. P., Vishwakarma, H., Ghosh, G., Gaikwad, K., Chellapilla, T. S., Singh, M. P., et al. (2020). Novel ASR isolated from drought stress responsive SSH library in pearl millet confers multiple abiotic stress tolerance in PgASR3 transgenic arabidopsis. Plant Physiol. Biochem. 156, 7-19. doi: 10.1016/j.plaphy.2020.07.031

Meuwissen, T. H., Hayes, B. J., and Goddard, M. E. (2001). Prediction of total genetic value using genome-wide dense marker maps. Genetics 157, 1819-1829. doi: 10.1093/genetics/157.4.1819

Mishra, R. N., Reddy, P. S., Nair, S., Markandeya, G., Reddy, A. R., Sopory, S. K., et al. (2007). Isolation and characterization of expressed sequence tags (ESTs) from subtracted cDNA libraries of Pennisetum glaucum seedlings. Plant. Mol. Biol. 64, 713-732. doi: 10.1007/s11103-007-9193-4

Morgan, R. N., Wilson, J. P., Hanna, W. W., and Ozias-Akin, P. (1998). Molecular markers for rust and Pyricularia leaf spot disease resistance in pearl millet. Theor. Appl. Genet. 96, 413-420.

Moumouni, K. H., Kountche, B. A., Jean, M., Hash, C. T., Vigouroux, Y., Haussmann, B. I., et al. (2015). Construction of a genetic map for pearl millet, Pennisetum glaucum (L.) R. Br., using a genotyping-by- sequencing (GBS) approach. Mol. Breed. 35, 5-10. doi: 10.1007/s11032-015-0212-x

Nambiar, V. S., Dhaduk, J. J., Sareen, N., Shahu, T., and Desai, R. (2011). Potential functional implications of pearl millet (Pennisetum glaucum) in health and disease. J. Appl. Pharm. Sci. 1, 62-67.

Nantanga, K. K. M. (2006). Lipid stabilization and partial precooking of pearl millet by thermal treatments (12-105) (MSc (Agric.) thesis). Food Science and Technology: Department of Food Science, Faculty of Natural and Agricultural Sciences, University of 19 Pretoria. Available online at: http://repository.up.ac. $\mathrm{za} /$ bitstream/handle/2263/26680/dissertation.pdfsequence $=1$

Nayaka, S. C., Shetty, H. S., Satyavathi, C. T., Yadav, R. S., Kavi Kishor, P. B., and Nagarajud, M., et al. (2017). Draft genome sequence of Sclerospora graminicola the pearl millet downy mildew pathogen. Biotechnol. Rep. 16, 18-20. doi: 10.1016/j.btre.2017.07.006 
Neeraja, C. N., Babu, V. R., Ram, S., Hossain, F., Hariprasanna, K., Rajpurohit, B. S. et al. (2017). Biofortification in cereals: progress and prospects. Curr Sci. 113:6. doi: $10.18520 / \mathrm{cs} / \mathrm{v} 113 / \mathrm{i} 06 / 1050-1057$

Obilana, A.B., and Manyasa, E. (2002). "Millets". in Pseudocereals and Less Common Cereals: Grain Properties and Utilization Potential, eds P. S. Belton and J. R. N. Taylor (Berlin, Heidelberg New York, NY: Springer-Verlag), 177-217.

Pawar, V. Y., Kute, N. S., Magar, N. M., and Patil, H. T. (2018). Genotypex environment interactions for grain micronutrient contents in pearl millet [Pennisetum glaucum (L.) R. Br.]. J. Pharma. Phytochem. 7, 37-44.

Poland, J. A., and Rife, T. W. (2012). Genotyping-by-sequencing for plant breeding and genetics. Plant Genome. 5, 92-102. doi: 10.3835/plantgenome2012.05.0005

Ponnaiah, G., Gupta, S. K., Blümmel, M., Marappa, M., Pichaikannu, S., Das, R., et al. (2019). Utilization of molecular marker based genetic diversity patterns in hybrid parents to develop better forage quality multi-cut hybrids in pearl millet. Agriculture 9:97. doi: 10.3390/agriculture9050097

Prakash, G., Kumar, A., Sheoran, N., Aggarwal, R., Satyavathi, C. T., Chikara, S. K., et al. (2019). First draft genome sequence of a pearl millet blast pathogen, Magnaporthe grisea strain $\mathrm{PMg}$ _ Dl, obtained using PacBio single-molecule real-time and Illumina NextSeq 500 sequencing. Microbiol. Resour. Announc. 8, e01499-e01418. doi: 10.1128/MRA.01499-18

Pujarula, V., Pusuluri, M., Bollam, S., Das, R. R., Ratnala, R., Adapala, G., et al. (2021). Genetic variation for nitrogen use efficiency traits in global diversity panel and parents of mapping populations in pearl millet. Front. Plant Sci. 12:625915. doi: 10.3389/fpls.2021.625915

Punnauri, S. M., Wallace, J. G., Knoll, J. E., Hyma, K. E., Mitchell, S. E., Buckler, E. S., et al. (2016). Development of a high-density linkage map and tagging leaf spot resistance in pearl millet using genotyping-by-sequencing markers. Plant Genome 9, 1-13. doi: 10.3835/plantgenome2015.10.0106

Qi, X., Lindup, S., Pittaway, T. S., Allouis, S., Gale, M. D., and Devos, K. M. (2001). Development of simple sequence repeat markers from bacterial artificial chromosome without sub-cloning. Biotechniques 31, 355-362.

Qi, X., Pittaway, T. S., Lindup, S., Liu, H., Waterman, E., Padi, F. K., et al. (2004). An integrated genetic map and a new set of simple sequence repeat markers for pearl millet (Pennisetum glaucum). Theor. Appl. Genet. 109, 1485-1493. doi: 10.1007/s00122-004-1765-y

Raheem, D., Dayoub, M., Birech, R., Nakiyemba, A. (2021). The contribution of cereal grains to food security and sustainability in Africa: potential application of UAV in Ghana, Nigeria, Uganda, and Namibia. Urban Sci. 5:8. doi: 10.3390/urbansci5010008

Rai, K. N., Govindaraj, M., and Rao, A. S. (2012). Genetic enhancement of grain iron and zinc content in pearl millet. Qual. Assur. Saf. Crops Foods. 4, 119-125. doi: 10.1111/j.1757-837X.2012.00135.x

Rai, K. N., Patil, H. T., Yadav, O. P., Govindaraj, M., Khairwal, I. S., Cherian, B., et al. (2014). Dhanashakti: a high-iron pearl millet variety. Indian Farm. 64, 32-34. Available online at: http://oar.icrisat.org/id/eprint/8602

Rai, K. N., Yadav, O. P., Govindaraj, M., Pfeiffer, W. H., Yadav, H. P., Rajpurohit, B. S., et al. (2016). Grain iron and zinc densities in released and commercial cultivars of pearl millet (Pennisetum glaucum). Indian J. Agri. Sci. 86, 11-16. Available online at: https://www.researchgate.net/profile/Mahalingam_ Govindaraj/publication/299597833_Grain_iron_and_zinc_densities_in_ released_and_commercial_cultivars_of_pearl_millet_Pennisetum_glaucum/ links/57020cca08aee995dde8e0f3.pdf

Rai, K. N., Yadav, O. P., Rajpurohit, B. S., Patil, H. T., Govindaraj, M., Khairwal, I. S., et al. (2013). Breeding pearl millet cultivars for high iron density with zinc density as an associated trait. J. SAT Agric. Res. 11, 1-7. Available online at: http://oar.icrisat.org/id/eprint/7291

Rajaram, V., Nepolean, T., Senthilvel, S., Varshney, R. K., Vadez, V., Srivastava, R. K., et al. (2013). Pearl millet [Pennisetum glaucum (L.) R. Br.] consensus linkage map constructed using four RIL mapping populations and newly developed EST-SSRs. BMC Genomics 14:159. doi: 10.1186/1471-2164-14-159

Ramu, P., Deshpande, S. P., Hash, C. T., Shah, T., Upadhyaya, H. D., RieraLizarazu, O., et al. (2013). Population genomic and genome-wide association studies of agroclimatic traits in sorghum. Proc. Natl. Acad. Sci. USA. 110, 453-458. doi: 10.1073/pnas.1215985110

Ramya, A. R., Ahamed, M. L., Satyavathi, C. T., Rathore, A., Katiyar, P., Raj, A. G., et al. (2018). Towards defining heterotic gene pools in pearl millet [Pennisetum glaucum (L.) R. Br.]. Front. Plant Sci. 8:1934. doi: 10.3389/fpls.2017. 01934
Rani, S., Singh, R., Sehrawat, R., Kaur, B. P., and Upadhyay, A. (2018). Pearl millet processing: a review. Nutr. Food Sci. 48, 30-44. doi: 10.1108/NFS-04-2017-0070

Rao, P. P., Birthal, P. S., Reddy, B. V., Rai, K. N., and Ramesh, S. (2006). Diagnostics of sorghum and pearl millet grains-based nutrition in India. Int. Sorghum Millets News Lett. 47, 93-96.

Reddy, P. S., Reddy, G. M., Pandey, P., Chandrasekhar, K., and Reddy, M. K. (2012). Cloning and molecular characterization of a gene encoding late embryogenesis abundant protein from Pennisetum glaucum: protection against abiotic stresses. Mol. Biol. Rep. 39, 7163-7174. doi: 10.1007/s11033-012-1548-5

Rooney, L. W. (1978). Sorghum and pearl millet lipids. Cereal Chem. 55, 584-590.

Saïdou, A. A., Clotault, J., Couderc, M., Mariac, C., Devos, K. M., and Thuillet, A. C. (2014). Association mapping, patterns of linkage disequilibrium and selection in the vicinity of the PHYTOCHROME C gene in pearl millet. Theor. Appl. Genet. 127, 19-32. doi: 10.1007/s00122-013-2197-3

Saïdou, A. A., Mariac, C., Luong, V., Pham, J. L., Bezançon, G., and Vigouroux, Y. (2009). Association studies identify natural variation at PHYC linked to flowering time and morphological variation in pearl millet. Genetics 182, 899-910. doi: 10.1534/genetics.109.102756

Sankar, S. M., Satyavathi, C. T., Barthakur, S., Singh, S. P., Bharadwaj, C., and Soumya, S. L. (2021). Differential modulation of heat inducible genes across diverse genotypes and molecular cloning of a sHSP from Pearl millet [Pennisetum glaucum (L). R. Br]. Front Plant Sci. 12:659893. doi: 10.3389/fpls.2021.659893

Satyavathi, C. T. (2017). Proceedings of 52nd Annual Group Meet, ICAR-All India Coordinated Research Program on Pearl millet, Jodhpur held at Punjab Agricultural University Ludhiana (Punjab) during April 28-30, 2017.

Satyavathi, C. T., Khandelwal, V., Supriya, A., Beniwal, B. R., Sushila, B., Mahesh, C. K., et al. (2020). Pearl Millet-Hybrids and Varieties- 2020. Jodhpur: ICAR-All India Coordinated Research Project on Pearl Millet.

Satyavathi, C. T., Sankar, S. M., Singh, S. P., Bhowmick, P., Bhat, J., Singh, O., et al. (2015). Stability analysis of grain iron and zinc content in pearl millet (Pennisetum glaucum (L.) R. Br). Int. J. Trop. Agric. 33, 1387-1394.

Satyavathi, CT., Tiwari, S, Bharadwaj, C., Rao, A.R., Bhat, J, and Singh, S.P. (2013). Genetic diversity analysis in a novel set of restorer lines of pearl millet [Pennisetum glaucum (L). R.Br] using SSR markers. Vegetos 26, 72-82. doi: 10.5958/j.2229-4473.26.1.011

Sehgal, D., Rajaram, V., Armstead, I. P., Vadez, V., Yadav, Y. P., Hash, C. T., et al. (2012). Integration of gene-based markers in a pearl millet genetic map for identification of candidate genes underlying drought tolerance quantitative trait loci. BMC Plant Biol. 12:9. doi: 10.1186/1471-2229-12-9

Sehgal, D., Skot, L., Singh, R., Srivastava, R. K., Das, S. P., Taunk, J., et al. (2015). Exploring potential of pearl millet germplasm association panel for association mapping of drought tolerance traits. PLoS ONE.10:e0122165. doi: 10.1371/journal.pone.0122165

Senthilvel, S., Jayashree, B., Mahalakshmi, V., Kumar, P. S., Nakka, S., Nepolean, T., et al. (2008). Development and mapping of simple sequence repeat markers for pearl millet from data mining of expressed sequence tags. BMC Plant Biol. 8:119. doi: 10.1186/1471-2229-8-119

Senthilvel, S., Nepolean, T., Supriya, A., Rajaram, V., Kumar, S., Hash, C. T., et al. (2010). "Development of a molecular linkage map of pearl millet integrating DArT and SSR markers". in Proc Plant Animal Genome 18 Conference (San Diego, CA), 9-13.

Serba, D. D., Muleta, K., Amand, P., St. Bernardo, A., Bai, G., Perumal,R., et al. (2019). Genetic diversity, population structure, and linkage disequilibrium of pearl millet. Plant Genom. 12:180091. doi: 10.3835/plantgenome2018.11.0091

Serba, D. D., and Yadav, R. S. (2016). Genomic tools in pearl millet breeding for drought tolerance: status and prospects. Front. Plant Sci. 7:1724. doi: 10.3389/fpls.2016.01724

Serba, D. D., Yadav, R. S., Varshney, R. K., Gupta, S. K., Mahalingam, G., Srivastava, R. K., et al. (2020). "Genomic designing of pearl millet: a resilient crop for arid and semi-arid environments", in Genomic Designing of Climate-Smart Cereal Crops, ed C. Kole (Springer Nature), 221-286. doi: 10.1007/978-3-319-93381-8_6

Serraj, R., Hash, C. T., Rizvi, S. M., Sharma, A., Yadav, R. S., and Bidinger, F. R. (2005). Recent advances in marker-assisted selection for drought tolerance in pearl millet. Plant Prod. Sci. 8, 334-337. doi: 10.1626/pps.8.334

Sharma, P. C., Singh, D., Sehgal, D., Singh, G., Hash, C. T., and Yadav, R. S. (2014). Further evidence that a terminal drought tolerance QTL of pearl millet 
is associated with reduced salt uptake. Environ. Exp. Botany. 102, 48-57. doi: 10.1016/j.envexpbot.2014.01.013

Sharma, S., Sharma, R., Govindaraj, M., Mahala, R. S., Satyavathi, C. T., Srivastava, R. K., et al. (2021). Harnessing wild relatives of pearl millet for germplasm enhancement: challenges and opportunities. Crop Sci. (TSI). 61, 177-200. doi: $10.1002 / \csc 2.20343$

Shivhare, R., Asif, M. H., and Lata, C. (2020). Comparative transcriptome analysis reveals the genes and pathways involved in terminal drought tolerance in pearl millet. Plant Mol. Biol. 103, 639-652. doi: 10.1007/s11103-020-01 015-w

Siddaiah, C. N., Prasanth, K. V. H, Satyanarayana, N. R., Mudili, V., Gupta, V. K., Kalagatur, N, K., et al. (2018). Chitosan nanoparticles having higher degree of acetylation induce resistance against pearl millet downy mildew through nitric oxide generation. Sci. Rep. 8, 1-14. doi: 10.1038/s41598-017-19016-z

Singh, J., Reddy, P. S., Reddy, S., and Reddy, M. (2015). Molecular cloning and characterization of salt inducible dehydrin gene from the C4 plant Pennisetum glaucum. Plant Gene. 4, 55-63. doi: 10.1016/j.plgene.2015.08.002

Singh, N., Singh, S. P., Kumar, M., Kanhiya, K., and Kumar, A. (2018). Nutricereal pearl millet: way forward. Int. J. Curr. Microbiol. App. Sci. 7, 578-581. doi: 10.20546/ijcmas.2018.706.066

Singh, S. D., Wilson, J. P., Navi, S. S., Talukdar, B.S., Hess, D.E., and Reddy, K. N. (1997). Screening techniques and sources of resistance to downy mildew and rust in pearl millet. Information Bulletin No. 48. Int. Crops Res. Instit. Semi-Arid Trop. Patancheru Andhra Pradesh India. 36:110.

Singh, S. P., Satyavathi, C. T., and Sankar, S. M. (2014). "Hybrid breeding in pearl millet: past and present status". in H. S. Chawla, P. K. Shrotria, and A. S. Jeena, eds New Paradigms in Heterosis Breeding: Conventional and Molecular Approaches (New Delhi: Indian Agric Stat Res Inst).

Singhal, T., Satyavathi, C.T., Kumar, A., Sankar, S. M., Singh, S. P., Bharadwaj, C., et al. (2018). Genotypex environment interaction and genetic association of grain iron and zinc content with other agronomic traits in RIL population of pearl millet. Crop Pasture Sci. 69, 1092-1102. doi: 10.1071/CP18306

Singhal, T., Satyavathi, C. T., Singh, S. P., Kumar, A., Sankar, S. M., Bharadwaj, C., et al. (2021). Multi environment quantitative trait loci mapping for grain iron and zinc content using biparental recombinant inbred line population in pearl millet. Front. Plant Sci. 12:659789. doi: 10.3389/fpls.2021.659789

Srivastava, R. K., Bollam, S., Pujarula, V., Pusuluri, M., Singh, R. B., Potupureddi, G., et al. (2020b). Exploitation of heterosis in pearl millet: a review. Plants. 9:807. doi: 10.3390/plants9070807

Srivastava, R. K., Singh, R. B., Lakshmi, V., Srikanth P., Pusuluri B., Satyavathi M., et al. (2020a). Genome wide association studies and genomic selection in Pearl millet: Advances and Prospects. Front. Genet. 10:1389. doi: 10.3389/fgene.2019.01389

Stein, A. J, Qaim, M., Meenakshi, J. V., Nestel, P., Sachdev, H. P. S., and Bhutta, Z. A. (2007). "Biofortification, an agricultural micronutrient intervention: its potential impact and cost-effectiveness". in: Consequences and Control of Micronutrient Deficiencies: Science, Policy, and Programs, April 16-18 (Istanbul).

Sun, M., Huang, D., Zhang, A., Khan, I, Yan, H., Wang, X., et al. (2020). Transcriptome analysis of heat stress and drought stress in pearl millet based on Pacbio full-length transcriptome sequencing. BMC Plant Biol. 20, 1-15. doi: 10.1186/s12870-020-02530-0

Supriya, A., Senthilvel, S., Nepolean, T., Eshwar, K., Rajaram, V., Shaw, R., et al. (2011). Development of a molecular linkage map of pearl millet integrating DArT and SSR markers. Theor. App. Genet. 123, 239-250. doi: 10.1007/s00122-011-1580-1

Taunk, J., Sehgal, D., Yadav, N. R., Howarth, C., Yadav, R. C., and Yadav, R. S. (2018). Mapping of easy to screen SSR markers for selection of RFLP markersbracketed downy mildew resistance QTLs in pearl millet. Eur. J. Plant Pathol. 151, 401-411. doi: 10.1007/s10658-017-1381-8

Thakur, R. P., and King, S. B. (1988). Registration of six smut resistant germplasms of pearl millet. Crop Sci. 28, 382-383. doi: 10.2135/cropsci1988.0011183X002800020058x

Thakur, R. P., Rai, K. N., Khairwal, I. S., and Mahala, R. S. (2008). Strategy for downy mildew resistance breeding in pearl millet in India. J SAT Agric Res. 6, 1-11.

Tharanya, M., Kholova, J., Sivasakthi, K., Seghal, D., Hash, C.T., Raj, B., et al. (2018). Quantitative trait loci (QTLs) for water use and crop production traits co-locate with major QTL for tolerance to water deficit in a fine mapping population of pearl millet (Pennisetum glaucum L. R.Br.) Theor. Appl. Genet. 131:1509-29. doi: 10.1007/s00122-018-3094-6

Uppal, R. K., Wani, S. P., Garg, K K., and Alagarswamy, G. (2015). Balanced nutrition increases yield of pearl millet under drought. Field Crop Res. 177, 86-97. doi: 10.1016/j.fcr.2015.03.006

Varshney, R. K., Shi, C., Thudi, M., Mariac, C., Wallace, J., Qi, P., et al. (2017) Pearl millet genome sequence provides a resource to improve agronomic traits in arid environments. Nat. Biotechnol. 35:969. doi: 10.1038/nbt.3943

Velu, G., Rai, K. N., Muralidharan, V., Kulkarni, V. N., Longvah, T., and Raveendran, T. S. (2007). Prospects of breeding biofortified pearl millet with high grain iron and zinc content. Plant Breed. 126, 182-185. doi: 10.1111/j.1439-0523.2007.01322.x

Verma, D., Singla-Pareek, S. L., Rajagopal, D., Reddy, M. K., and Sopory, S. K. (2007). Functional validation of a novel isoform of $\mathrm{Na}+/ \mathrm{H}+$ antiporter from Pennisetum glaucum for enhancing salinity tolerance in rice. J. Biosci. 32, 621-628. doi: 10.1007/s12038-007-0061-9

Weckwerth, W., Ghatak, A., Bellaire, A., Chaturvedi, P., and Varshney, R. K. (2020). PANOMICS meets germplasm. Plant Biotechnol. J. 18, 1507-1525. doi: $10.1111 /$ pbi. 13372

Yadav, O.P., and Rai, K. N. (2013). Genetic improvement of pearl millet in India. Agric. Res. 2, 275-292. doi: 10.1007/s40003-013-0089-z

Yadav, O. P., Gupta, S. K., Govindara, J. M., Sharma, R., Varshney, R. K., Srivastava, R. K., et al. (2021). Genetic gains in pearl millet in India: insights into historic breeding strategies and future perspective. Front. Plant Sci. 12:645038. doi: 10.3389/fpls.2021.645038

Yadav, O. P., Singh, D. V., Dhillon, B. S., and Mohapatra, T. (2019). India's evergreen revolution in cereals. Curr. Sci. 116, 1805-1808. doi: 10.18520/cs/v116/i11/180 5-1808

Yadav, R. S., Hash, C. T., Bidinger, F. R., Cavan, G. P., and Howarth, C. J. (2002). Quantitative trait loci associated with traits determining grain and stover yield in pearl millet under terminal drought stress conditions. Theor. Appl. Genet. 104, 67-83. doi: 10.1007/s0012202 00008

Yadav, R. S., Hash, C. T., Bidinger, F. R., Devos, K. M., and Howarth, C. J. (2004). Genomic regions associated with grain yield and aspects of post flowering drought tolerance in pearl millet across stress environments and tester background. Euphytica. 136, 265-277. doi: 10.1023/B:EUPH.0000032711.34 $599.3 \mathrm{a}$

Yadav, R. S., Hash, C. T., Bidinger, F. R., and Howarth,C. J. (1999). "QTL analysis and marker-assisted breeding of traits associated with drought tolerance in pearl millet". in Genetic Improvement of Rice for Water-Limited Environments, eds O. Ito, J. O'Toole, and B. Hardy (Manila: International Rice Research Institute), 221-233.

Yadav, R. S., Sehgal, D., and Vadez, V. (2011). Using genetic mapping and genomics approaches in understanding and improving drought tolerance in pearl millet. J. Exp. Bot. 62, 397-408. doi: 10.1093/jxb/ erq265

Conflict of Interest: The authors declare that the research was conducted in the absence of any commercial or financial relationships that could be construed as a potential conflict of interest.

Publisher's Note: All claims expressed in this article are solely those of the authors and do not necessarily represent those of their affiliated organizations, or those of the publisher, the editors and the reviewers. Any product that may be evaluated in this article, or claim that may be made by its manufacturer, is not guaranteed or endorsed by the publisher.

Copyright (c) 2021 Satyavathi, Ambawat, Khandelwal and Srivastava. This is an open-access article distributed under the terms of the Creative Commons Attribution License (CC BY). The use, distribution or reproduction in other forums is permitted, provided the original author(s) and the copyright owner(s) are credited and that the original publication in this journal is cited, in accordance with accepted academic practice. No use, distribution or reproduction is permitted which does not comply with these terms. 